\title{
A Two-Factor Uncertainty Model to Determine the Optimal Contractual Penalty for a Build-Own-Transfer Project
}

\author{
João Adelino Ribeiro, Paulo Jorge Pereira and Elísio Brandão ${ }^{\dagger}$
}

January 14, 2014

\begin{abstract}
Public-Private Partnerships (PPP) became one of the most common types of public procurement arrangements and Build-Own-Transfer (BOT) projects, awarded through adequate bidding competitions, have been increasingly promoted by governments. The theoretical model herein proposed is based on a contractual framework where the government grants leeway to the private entity regarding the timing for project implementation. However, the government is aware that delaying the beginning of operations will lead to the emergence of social costs, i.e., the costs that result from the corresponding loss of social welfare. This fact should motivate the government to include a contractual penalty in case the private firm does not implement the project immediately. The government also recognizes that the private entity is more efficient in constructing the project facility. The model's outcome is the optimal value for the legal penalty the government should include in the contract form. A two-factor uncertainty approach is adopted and Adkins and Paxson (2011) quasi-analytical solution is applied since homogeneity of degree one can not be invoked in all of the model's boundary conditions. Sensitivity analysis reveals that variations in the correlation coefficients have a strong impact on the optimal contractual penalty and also that there is a level for the comparative efficiency factor above which there is no need to impose a contractual penalty, for a given level of social costs. Finally, the effects of including a non-optimal penalty value in the contract form, which derives from overestimating or underestimating the selected bidder's real comparative efficiency are examined, using a numerical example. Results demonstrate that overestimating (underestimating) the selected bidder's real comparative efficiency leads to the inclusion of a below-optimal (above-optimal) value for the legal penalty in the contract and produces effects that the government would prefer to prevent.
\end{abstract}

JEL Classification Codes: G31; D81.

Keywords: real options; two-factor uncertainty models; public-private partnerships; optimal contractual penalty.

${ }^{*} \mathrm{PhD}$ in Finance (Porto Faculty of Economics); email: joaoadelinoribeiro@ gmail.com

${ }^{\dagger}$ Assistant Professor at Faculty of Economics, University of Porto, Portugal; email: pjpereira@ fep.up.pt

\$Full Professor at Faculty of Economics, University of Porto, Portugal; email: ebrandao@ fep.up.pt 


\section{Part I}

\section{Introduction}

\section{Review of the Literature}

\subsection{Build-Operate-Transfer (BOT) Projects in the Context of Bidding Competi- tions}

Public-Private Partnerships (PPP) became one of the most important types of public procurement arrangements and its importance has been growing considerably in the last decades (Kwak et al. (2009); Alonso-Conde et al. (2007); Algarni et al. (2007); Ho and Liu (2002)). PPP is usually defined as a long-term development and service contract between the government and a private partner (Maskin and Tirole (2008)). This type of contract may assume different forms and the Build-Own-Transfer (BOT) model is widely adopted (Liu and Cheah (2009); Ho and Liu (2002)). BOT is the terminology for a project structure that uses private investment to undertake the infrastructure development, and which has been historically ensured by the public sector. ${ }^{1}$ In fact, the private sector has been playing an increasingly crucial role in the financing and provision of services that were traditionally in the domain of the public sector. One of the key reasons is that governments are unable to cope with the ever-increasing demands on their budgets. Most infrastructure expenditures in developing - and also in developed countries - have been funded directly from fiscal budgets but several factors such as the macroeconomic instability and growing investment needs have shown that public finance is volatile and, in many of those countries, rarely meet the infrastructure expenditure requirements in a timely and adequate manner (Ferreira and Khatami (1996)).

In BOT projects, a private entity is given a concession to build an infrastructure and operate a facility which, as we just mentioned, would traditionally be built and operated by the government or a public agent (Shen and Wu (2005)). At the end of the predetermined concession period (a period that tends to be long), the private party returns the ownership of the infrastructure to the government or the public entity (Shen et al. (2002)). ${ }^{2}$

\footnotetext{
${ }^{1}$ The acronym BOT is often used interchangeably with BOOT (build-own-operate-transfer). Other arrangements include BOO (build-own-operate), a type of contractual scheme where the private party does not carry the obligation of transferring the ownership in any date, meaning that the private partner may operate the facility forever, as in the case of a typical private investment project.

${ }^{2}$ Given that BOT/BOOT schemes are designed and implemented as Public-Private Partnership contractual arrangements, we will consider, for the purpose of the present work, BOT and PPP designations as being synonyms.
} 
BOT infrastructure projects also differ significantly from the construction projects we have considered in Chapters II and III in how they are implemented during the preconstruction phase. In the case of construction projects, the public party is responsible for project planning, property acquisition and, more importantly, project funding. For BOT projects, the concessionaire (private party) is usually required to undertake these project development tasks (Huang and Chou (2006)). This contractual arrangement provides a mechanism for using private finance, hence allowing the public sector to construct more infrastructure services without the use of additional public funds (Shen and Wu (2005)) .

BOT projects are awarded through an appropriate bidding competition process, where a number of private entities compete to win the contract. As with the other type of construction projects - and all other things being equal - the contract will be awarded to the bidder that presented the most competitive bid, which, in the case of BOT projects, means the bidder that offered the highest price. ${ }^{3}$ The price is the amount to be paid to the government to own the right to operate the facility once the obligation of constructing the infrastructure is fulfilled. Hence, the selected bidder will be invited to sign the contract and - if the contract is actually signed - he or she will have to invest in constructing the facility and run the subsequent operations, once the construction phase is completed.

\subsection{The Application of the Real Options Approach to BOT Projects}

A considerable number of research pieces can be found where the real options approach is applied to address different questions concerning BOT projects. Some of the most important issues concern project valuation, how several risk types should be shared between the parties, the role of incentives and subsidies given by the government or the public agent and also the well-known mechanism of the Minimum Revenue Guarantee (MRG). By addressing these topics using the real options approach, researchers acknowledge that this methodology seems to be the most adequate, since a number of real options are available to both parties throughout the life of the project. Thus, flexibility is a feature that can be frequently found on existing contracts and the levels of uncertainty surrounding this type of projects tend to be high. By recognizing the irreversibility of this type of investments and also the uncertainty and flexibility that characterizes BOT projects, some researchers adopt the real options approach to evaluate options embedded in current contract types, while others use it to sustain and propose different forms of shaping contracts between the parties, namely by suggesting that incorporating more flexibility in the contractual

\footnotetext{
${ }^{3}$ In construction projects - and all other things being equal - the selected bidder is the one that presented the lowest bid. For obvious reasons, in a BOT project competitive bid, is the other way around: all else equal, the selected bidder will be the one that offered the highest price.
} 
relationship may lead to more economic efficiency at different levels. Various research pieces can be found focusing on one or more of the above research topics. For example, Huang and Chou (2006) valued the MRG and the option to abandon the project by the private firm, and Brandao and Saraiva (2008) also developed a model for infrastructure projects based on the consideration of a Minimum Demand Guarantee. Cheah and Liu (2006) addressed the valuation of demand and revenue guarantees, applying Monte Carlo simulation, and Chiara et al. (2007) also applied the same technique to evaluate a MRG, which is only redeemable at specific moments in time. Alonso-Conde et al. (2007) addressed the existing contractual conditions in PPP which guarantee a minimum profitability to the private firm. Shan et al. (2010) proposed collar options (a call option and a put option combined) to better manage revenue risks. Huang and Pi (2009) applied a sequential compound option approach for valuing multi-stage BOT projects, in the presence of dedicated assets. Caselli et al. (2009) valued the indemnification provision that ensures a final compensation to the private partner, in the event the government terminates a BOT contract. Armada et al. (2012) showed how the net cost of incentives, which may be given by the government to induce the immediate investment, should equal the value of the option to defer the beginning of operations by the private firm. Pereira et al. (2006) applied a two-factor uncertainty model aiming to reach the optimal timing for the construction of an international airport, where the cash-flows to be generated were disaggregated into the number of passengers and the net cash-flow "per passenger". Their model is thus based on the existence of two stochastic variables, but they considered the investment costs constant.

\subsection{Two-Factor Uncertainty Models in the Real Options Literature}

All of the above research pieces do not consider the two key-value drivers of a BOT project - the construction costs and cash-flows to be generated by operations - as stochastic variables. To the best of our knowledge, the only research piece based on a two-factor uncertainty model, in the context of BOT projects, where the stochastic variables are the present value of the cash-flows and the construction costs is the paper by Ho and Liu (2002). In fact, these researchers considered the construction costs and the present value of cash-flows as being both stochastic variables, behaving according to Geometric Brownian Motions. However, their model is designed in discrete time, more specifically applying the well-known binomial model, with the purpose of valuing a debt guarantee given by the government, and also accounting for the risk of bankruptcy. The model we propose and describe in Section 4.3 is a two-factor uncertainty model in continuous time, where both construction costs and cash-flows follow geometric Brownian motions that 
are possibly correlated and, to the best of our knowledge, is the first model apllying a two-factor uncertainty approach in continuous-time, in the context of BOT projects.

In fact, the consideration of both key-value drivers of BOT projects as stochastic variables is not a common feature in existing models. However, we should stress that, in recent years, two-factor uncertainty models have been increasingly adopted to address other research topics in the field of real options, such as the research pices carried out by Armada et al. (2013), Adkins and Paxson (2011) and Paxson and Pinto (2005).

The traditional real options model on the optimal timing to invest in a project with irreversible costs and generating perpetual cash-flows was first developed by McDonald and Siegel (1986), where both the value of expected cash-flows and the investment costs are considered to behave stochastically. This model is carefully explained in Dixit and Pindyck (1994). These authors describe the model but held the investment costs constant in a first stage. Later in their text book, Dixit and Pindyck (1994) address the bi-dimensionality issue - thus recognizing the stochastic nature of the investment costs - and present McDonald and Siegel (1986) solution, which consists of reducing the two stochastic variables to just one, by merely substituting the cash-flows and investment costs by a single variable (ratio) that equals the cash-flows divided by the investment costs. McDonald and Siegel (1986) model is also described in Trigeorgis (1996). Both Trigeorgis (1996) and Dixit and Pindyck (1994) stated that it is optimal to invest when the ratio between the expected cash-flows and the investment costs reaches a given boundary: the so-called "free boundary", separating the waiting region from the investing region. This method may be very useful to address some BOT projects related issues but, unfortunately, we cannot apply it to all situations in the context of the present work, since we can not invoke homogeneity of degree one in all the boundary conditions, unlike what happens in McDonald and Siegel (1986) model. ${ }^{4}$

The model we suggest is based on the recognition of uncertainty in both the facility construction costs and in the value of the cash-flows that will be generated by operating the project facility, which means that a two-factor uncertainty framework will be adopted, with both variables following geometric Brownian motions that are possibly correlated. In the next Section, we detail the proposed framework, where the government grants leeway to the selected firm regarding the timing for project implementation, which means that the private firm may implement the project when he or she decides that is optimal to do so. However, we propose that a contractual penalty should be established in the event the private firm does not implement the project immediately. The theoretical model

\footnotetext{
${ }^{4}$ Since their boundary conditions do not infringe homogeneity of degree one, the model proposed by these researchers respect the condition which states that the sum of the roots of the quadratic equation equals 1 . A closed-form solution is thus reached.
} 
aims to determine the optimal level for this contractual penalty. The determination of the optimal level for this penalty will consider the argument that the selected firm is more efficient than the government in executing the project facility, and also that the government recognizes the existence of social costs, i.e., the costs that correspond to the loss of social welfare, which emerge if the project is not implemented immediately. If we consider that both entities are equally efficient, then the optimal penalty would be the one that would induce the selected firm to invest in the same moment the government would, if the government decided to undertake the project. However, we will demonstrate that by assuming that the private firm is more efficient than the government in executing the project facility - the optimal contractual penalty is the one that makes the private firm invest when his or her value for the cash-flows trigger equals the value of the government cash-flows trigger, for a given project dimension and assuming a specific level of comparative efficiency. In fact, by considering that the private firm is more efficient, then one would expect the private firm to invest sooner than the government: he or she will attain his or her construction costs trigger sooner than the government will attain its construction costs trigger. By attaining the construction costs trigger sooner than the government, and since the optimal contractual penalty is the one that makes both entities have the same trigger for the cash-flows, consequently one expects the private firm to invest sooner than the government would, if the government decided to conduct the project. In fact, by introducing the higher efficiency of the private firm in the model, we can not define the optimal penalty as being the one that makes both entities have the same combination of triggers, i.e., expectedly,to invest in same moment of time. Rather, in the presence of the private firm's higher efficiency, the optimal penalty should be defined as the one that moves the private firm cash-flows trigger downwards in order to meet the government cash-flows trigger, for a given project dimension and considering the estimated value for the comparative efficiency factor.

\section{Proposed Framework}

\subsection{Flexibility May Imply a Cost. The Contractual Penalty}

We define a conceptual framework where a BOT project may be undertaken by the government or then awarded to a private firm through an appropriate competitive bid process, maybe because the government recognizes that is less efficient than the private firm in executing the project. We suggest that the project may be initiated whenever the selected bidder decides it is optimal to do so, meaning that no contractual obligation for immediate initiation of activities is imposed by the government. This assumption regarding 
the absence of any contractual obligation regarding the immediate implementation of the project has also been adopted by Armada et al. (2012), and plays a crucial role in the context of the research questions they have addressed. The motivation of their research work lies on the argument that the private firm will start investing later than the government would like him or her to, since the option to defer the project implementation does have value. Bearing this in mind, they studied how certain subsidies and guarantees, granted to the private firm, can be optimally arranged with the purpose of inducing the immediate implementation of the project. We build the present framework on the same assumption but argue that, under certain conditions, a legal penalty should be enforced in the event the construction of the facility does not start immediately. Thus, and even though we acknowledge that the private firm may manage the project implementation as far as its initiation/completion is concerned, we suggest that a penalty should be enforced in the case the infrastructure is not ready and operations do not start immediately. This means that the private firm is aware of the fact that delaying the project implementation may grant him some benefits (there is value to waiting for more information) but is also aware that deferring the beginning of the project may entail a cost. Thus, the private firm has flexibility regarding the moment to start running operations but this flexibility may imply a cost. We propose that, under certain conditions, which we will discuss later on in this paper, this cost should be considered in the contract form, assuming the form of a legal penalty.

\subsection{The Importance of the Efficiency Factor}

We have to acknowledge that governments are, in most cases, less efficient than private firms in conducting BOT projects. This argument is common in the literature and is frequently invoked as being one of the reasons why governments actually grant the projects to the private sector (see, for example, Brandao and Saraiva (2008); Zhang and Kumaraswamy (2001)). Being so, one should expect the private firm to invest earlier due to its greater efficiency. To be more efficient means being able to construct the facility investing less money than the government would. Hence, if the expected constructions costs of the private firm are lower than the construction costs estimated by the government, then - all else equal - the private firm will attain the critical value for the cash-flows to be generated by operations that triggers the investment sooner than the government. This is the same as saying that one expects the private firm to invest in an earlier moment of time than the government would.

Hence, by considering that the private firm is more efficient than the government, we are assuming that the private firm will have a lower trigger for his or her construction costs 
than if both entities were considered to be equally efficient because, if both entities were equally efficient, then they would have the same construction costs trigger. This greater efficiency leads us to conclude that the efficiency factor places the firm construction costs trigger before the government construction costs trigger, "vis-a-vis" with the scenario where both entities are equally efficient. Furthermore, the greater the level of comparative efficiency, the lower the private firm construction costs trigger will be or, which is the same, the further backwards its construction costs trigger will be shifted, again when compared with the "equally efficient scenario".

Considering the private firm's greater efficiency, the government's purpose is accomplished if the private firm invests when his or her cash-flows trigger equals the government cash-flows trigger. We would like to underline this argument: by enforcing an optimal legal penalty, the government's purpose is to induce the private firm to invest when he or she has a cash-flows trigger whose value equals the value of the government cash-flows trigger. This implies that, without the enforcement of the legal penalty, the private firm cash-flows trigger will be higher than the government cash-flows trigger. We will show that this inequality holds since the government cash-flows trigger is affected by another crucial element that the model encompasses. We designate this element as "social costs".

\subsection{The Importance of Social Costs}

The traditional concept of "social cost" was addressed by Coase (1960) and is based on the concept of "externality", in the sense that, by producing a certain good, a harmful effect is caused to the society, rather than the owners of the firm responsible for the production of that good or its customers. It is a cost which society must ultimately bear. This naturally entails that a loss of welfare occurs to the population due to the emergence of this externality. Hence, this loss of welfare is not a direct consequence of the fact that a firm is not producing a good or providing a service to its customers. Rather, social cost is exactly defined as being the cost borne by the population because a certain good is being produced and such fact causes an undesirable effect to the population. Notwithstanding, we reason that, when a government or a government agency decides to implement a project, its goal is to provide a service to the population. The government decision of, say, implementing a High-Speed Rail service is based on the conviction that the project will generate a social benefit, as stated by Rus and Nombela (2007). Hence, the government believes that social benefits occur as soon as the project is implemented and operations start because social welfare will emerge once the project is completed. Bearing this important argument in mind, we state that, on the contrary, if the project is not implemented immediately, a loss of welfare occurs and this is the same as stating that the social benefits emerging from the 
immediate project implementation are postponed until the project is actually completed and the subsequent activities start. We thus argue that the lack of social benefits from the moment the project should have been ready and the moment the project is, in fact, ready and operations begin can be legitimately defined as "social costs". Social costs are, therefore, directly related with the loss of welfare that occurs if the project is not implemented immediately. Again, these costs correspond to the loss of social welfare occurred from the time the project should have been ready to start operating and providing services to its users and the moment operations actually begin and the users needs start being satisfied. Being so, our model considers the existence of social costs in the case the project is not implemented immediately.

Social costs, as we define them, are rarely negligible. Large-scale investments are undertaken because governments believe that public needs must be satisfied and such needs will only be satisfied once the project is completed and subsequent operations begin. The level of the social costs may be high for some projects, moderate for other projects or even low in fewer cases. ${ }^{6}$ We will consider that social costs are estimated by the government as being a percentage of the expected cash-flows to be generated by operations. By estimating an expected level of social costs, the government is setting its own cash-flows trigger or, which is the same, is defining the precise moment where the project would be initiated if the government decided to undertake the project. Nevertheless, when defining the moment where the project would be implemented, the government behaves as a rational agent, in the sense that also considers the benefits of waiting and invest in a later date (meaning that the government recognizes that there is value to waiting, regardless of which entity will conduct the project) and compares such benefits with the fact that, the later the project will be implemented, the higher the value of social costs will be. Thus, when the government sets its own cash-flows trigger, by defining the level of social costs considered to be tolerable, the government takes into account the fact that waiting for better information does have value. The government cash-flows trigger will thus result from a trade-off between the benefits of waiting and, hence, not invest immediately and the level of social costs to be borne by the population, if the project is not promptly initiated. We argue that, when establishing the level of social costs considered to be acceptable, the government also takes into account the benefits that derive from de-

\footnotetext{
${ }^{5}$ We would like to underline the argument that our definition of "social costs" differs from the definition of "social cost", as in Coase (1960). This means that we are not using this concept in the context of the present work since we are not considering the importance of the emergence of social cost(s), which result(s) from some kind of externality.

${ }^{6}$ Currently in Portugal, there is a stream of opinion that questions the benefits of some large-scale investments undertaken in the recent past, especially the construction of highways linking the cities of Lisbon and Porto, which are considered by many to be redundant. In such cases and following this line of thought, delaying the initiation of large-scale investments whose social benefits are perceived as being very low will entail a very low level of social costs.
} 
laying the project implementation. Consequently, the greater the level of social costs the government considers to be acceptable, the sooner the government would invest. On the contrary, for lower levels of acceptable social costs, the government will invest later. We will numerically demonstrate the existence of this relationship in Part II.

\subsection{The Definition of Optimal Contractual Penalty}

Social costs do play a fundamental role in establishing the optimal level for the contractual penalty to be enforced in the event the project is not initiated immediately. The greater the level of social costs the sooner the government would invest and the higher the optimal penalty needs to be, with the purpose of moving the cash-flows trigger downwards to meet the government cash-flows trigger, which is now placed more below. On the contrary, the lower the level of social costs the smaller the optimal penalty needs to be (since the government cash-flows trigger is now placed more above) and, if the level of social costs is zero, then a legal penalty is not needed, which is the same as saying that the optimal level is zero. Hence, we define the optimal value for the contractual penalty as the one that moves the private firm cash-flows trigger downwards with the purpose of meeting the government cash-flows trigger, assuming that the private firm cash-flows trigger is higher than the government cash-flows trigger. Bearing this definition in mind, we have to conclude that any value for the contractual penalty that does not move the private firm cash-flows trigger downwards in order to perfectly meet the government cash-flows trigger will never be optimal. In Part II, we will discuss the effects, to the government, that derive from including a non-optimal level for the legal penalty in the contract form.

The remainder of the present paper unfolds as follows. In Part II, the model is described and both the government decision to invest and the government expectation about the private firm decision to invest are presented. The optimal level for the contractual penalty "per unit" of cost is then reached, considering the effect of the estimated efficiency factor and also the effect caused by the level of social costs. We proceed to perform a sensitivity analysis, aiming to assess the impact of variations in various parameters of the model on the optimal contractual penalty. More specifically, we measure how the optimal value for the contractual penalty is affected by (i) changes in the level of social costs; (ii) changes in the efficiency factor; (iii) variations in both the level of social costs and the level of the comparative efficiency factor; (iv) variations in the correlation coefficients; (vi) variations in the standard deviations of both variables. Also, we derive an analytical solution to the level of the efficiency factor above which the inclusion of legal penalty is not justified, for a given level of social costs. Still in Part II, we examine the effects, to the government, of including a non-optimal value for the legal penalty in the contract from, as a direct result 
of overestimating or underestimating the comparative efficiency factor. Finally, in Part III, conclusions are given.

\section{Part II}

\section{The Model}

\subsection{Assumptions}

We assume that (i) the government has the necessary know-how to determine fair estimates about the construction costs and the cash-flows to be generated through operating the facility, as if the project was conducted by the government; (ii) the standard deviations of the facility construction costs and of the future cash-flows are the same for both the government and the private firm, since variations in the value of the project inputs and the project outputs are both observable in the markets; (iii) the rate of return-shortfalls (i.e., the "convenience yields") are also the same for both entities; (iv) the government recognizes that is less efficient in constructing the project facility than the private firm; (v) the government is capable of determining a fair estimate for the private firm's higher level of efficiency; (vi) the construction of the facility is assumed to be instantaneous; ${ }^{7}$ (vii) the project, once implemented, will generate perpetual cash-flows; ${ }^{8}$ (viii) the government incurs in social costs if the project is not completed and operations do not start immediately; (ix) social costs are assumed to be a percentage of the cash-flows to be generated by operations; $(\mathrm{x})$ the project dimension is given by the government's expected construction costs.

\subsection{Model Description}

\subsubsection{Introduction}

We depart from considering that the various sources of uncertainty underlying a BOT project may be reduced to two aggregated sources: the uncertainty regarding the value

\footnotetext{
${ }^{7} \mathrm{By}$ assuming that the construction of the facility is instantaneous, we are implicitly considering that no flexibility is present throughout the construction stage. Therefore, we exclude the existence of options during this stage. Since flexibility is not considered, we are only concerned with the fact that construction costs are uncertain.

${ }^{8} \mathrm{We}$ assume that the concession period is sufficiently long for the investment opportunity to be considered equivalent to a perpetual call option. This is a common assumption in the literature. See, for example, Armada et al. (2012).
} 
of the future cash-flows to be generated by operations, $V$, and the facility construction costs, $K$. In specific situations, we will follow Adkins and Paxson (2011) approach, also based on a two-factor uncertainty model, and consisting of a set of simultaneous equations. These authors developed a quasi-analytical solution, whereby a boundary between the continuance and the renewal regions (i.e., the boundary separating the regions where values for both variables justify an incumbent asset to continue operating or to be renewed and, thus, substituted by a new one by paying a fixed cost) is determined, since they are unable to invoke homogeneity of degree one in their model. We will show that some of the questions we propose to answer can not be addressed by invoking homogeneity of degree one, hence leading us to follow Adkins and Paxson (2011) approach. By considering that a trade-off exists between the two stochastic variables and also that only when both triggers are simultaneously attained investment is triggered, Adkins and Paxson (2011) state that a countless set of pairs for such triggers do exist, i.e., there is an infinite combination of possible threshold values for both variables. In our model, it is possible to envisage a countless pair of threshold values for the stochastic variables, $V^{*}$ and $K^{*}$ and also that this countless set of pairs defines the discriminatory boundary that separates the waiting region from the investing region. A variation in one of the variables leads to a variation of the same sign in the other for the investment to be triggered. In fact, lower construction costs will necessarily lead to a lower value of cash-flows to trigger the investment and, similarly, a higher value of construction costs will lead to a higher cash-flows value which triggers the investment. As Dixit and Pindyck (1994) point out, the value of the option to invest depends on both variables, which means that the option will be exercised when $V$ becomes sufficiently high for a given $K$ or $K$ becomes sufficiently low for a given $V$. On the contrary, if $V$ is not sufficiently large for a given $K$ or $K$ is too low for a given $V$, then one would expect the option to be held. Hence, we are aware that is possible to define an optimal boundary composed by a set of pairs for $V^{*}$ and $K^{*}$ that discriminates the waiting region from the investing region. We will denote this set of trigger values as $\left\{V^{*}, K^{*}\right\}$.

We proceed to present the base case parameter values and derive the government decision to invest, bearing in mind that social costs are present and considered to be a percentage of the cash-flows to be generated by operations. This implies that the government recognizes the fact that, if the project is not implemented immediately, a loss of social welfare occurs until the project is completed and operations actually start. We then derive the government expectation about the private firm investment decision, assuming the private firm is more efficient than the government in executing the project facility. Finally, we determine the optimal value for the contractual penalty "per unit" of cost, and consider three different project dimensions, for illustrative purposes.

For both cases, i.e., the government decision to invest and the expectation the government 
has about the private firm's decision to invest, the two stochastic variables (the value of the cash-flows to be generated by operations, $V$, and the facility construction costs, $K$ ) follow geometric Brownian motions that are possibly correlated. Let $i \in\{G, P\}$. Hence:

$$
\begin{gathered}
d V_{i}=\alpha_{V_{i}} V_{i} d t+\sigma_{V_{i}} V_{i} d z_{V_{i}} \\
d K_{i}=\alpha_{K_{i}} K_{i} d t+\sigma_{K_{i}} K_{i} d z_{K_{i}} \\
E\left(d z_{V_{i}} d z_{K_{i}}\right)=\rho_{i} d t
\end{gathered}
$$

where $\alpha_{V_{i}}$ and $\alpha_{K_{i}}$ are the drift parameters, $d t$ is the time interval, $\sigma_{V_{i}}$ and $\sigma_{K_{i}}$ the standard deviations for each of the variables, $d z_{V_{i}}$ and $d z_{K_{i}}$ the corresponding increments of standard Wiener processes and, finally, $\rho_{i}$ is the correlation coefficient between $V_{i}$ and $K_{i}$.

Table 1 includes the base case parameter values we will be using, unless otherwise mentioned.

Table 1: the base case parameter values

$$
\text { (for } i \in\{G, P\} \text { ) }
$$

\begin{tabular}{|c||c||c|}
\hline Parameters & Symbols & Values \\
\hline \hline standard deviation of the cash-flows & $\sigma_{V_{i}}$ & 0.15 \\
\hline \hline standard deviation of the construction costs & $\sigma_{K_{i}}$ & 0.10 \\
\hline \hline cash-flows rate of return-shortfall & $\delta_{V_{i}}$ & 0.03 \\
\hline \hline construction costs rate of return-shortfall & $\delta_{K_{i}}$ & 0.03 \\
\hline \hline correlation coefficient & $\rho_{i}$ & 0 \\
\hline \hline risk-free interest rate & $r$ & 0.05 \\
\hline \hline level of social costs & $s$ & 0.02 \\
\hline \hline comparative efficiency factor & $\gamma$ & 0.2 \\
\hline
\end{tabular}

\subsubsection{The Government Decision to Invest}

Under risk-neutrality, the value of the government investment opportunity, $F_{G}\left(V_{G}, K_{G}\right)$ must satisfy the following partial differential equation (Constantinides, 1978): 


$$
\begin{array}{r}
\frac{1}{2} \sigma_{V_{G}}^{2} V_{G}^{2} \frac{\partial^{2} F_{G}}{\partial V_{G}^{2}}+\frac{1}{2} \sigma_{K_{G}}^{2} K_{G}^{2} \frac{\partial^{2} F_{G}}{\partial K_{G}^{2}}+\rho \sigma_{V_{G}} \sigma_{K_{G}} V_{G} K_{G} \frac{\partial^{2} F_{G}}{\partial V_{G} \partial K_{G}}+ \\
\left(r-\delta_{V_{G}}\right) V_{G} \frac{\partial F_{G}}{\partial V_{G}}+\left(r-\delta_{K_{G}}\right) \frac{\partial F_{G}}{\partial K_{G}}-r F_{G}-s V_{G}=0
\end{array}
$$

where $r$ is the risk-free interest rate, $s V_{G}$ denotes the value of social costs as a percentage of the cash-flows to be generated by the project operations, $\delta_{V_{G}}$ and $\delta_{K_{G}}$ are the rates of return-shortfall for $V_{G}$ and $K_{G}$, respectively, which are given by the following equations:

$$
\begin{gathered}
\delta_{V_{G}}=r-\alpha_{V_{G}} \\
\delta_{K_{G}}=r-\alpha_{K_{G}}
\end{gathered}
$$

The following general solution satisfies the partial differential equation (4):

$$
F_{G}\left(V_{G}, K_{G}\right)=A_{1} V_{G}^{\beta^{+}} K_{G}^{\eta^{+}}+A_{2} V_{G}^{\beta^{+}} K_{G}^{\eta^{-}}+A_{3} V_{G}^{\beta^{-}} K_{G}^{\eta^{+}}+A_{4} V_{G}^{\beta^{-}} K_{G}^{\eta^{-}}-\frac{s}{\delta_{V_{G}}} V_{G}
$$

where $A_{1}, A_{2}, A_{3}$ and $A_{4}$ are constants that need to be determined. $\beta^{+}, \beta^{-}, \eta^{+}$and $\eta^{-}$ are the four roots of an elliptical equation, which is the two-factor counterpart of the onefactor stochastic model quadratic equation presented in Dixit and Pindyck (1994). The elliptical equation is:

$$
\begin{aligned}
Q(\beta, \eta)= & \frac{1}{2} \sigma_{V_{G}} \beta(\beta-1)+\frac{1}{2} \sigma_{K_{G}}^{2} \eta(\eta-1)+ \\
& \rho_{G} \sigma_{V_{G}} \sigma_{K_{G}} \beta \eta+\left(r-\delta_{V_{G}}\right) \beta+\left(r-\delta_{K_{G}}\right) \eta-r=0
\end{aligned}
$$

The function $Q(\beta, \eta)=0$ defines an ellipse. ${ }^{9}$ Equation (8) has four quadrants, to which of them corresponds a pair of the four roots just mentioned, i.e., the four points where the elliptic function meets the axes. If we now consider the absorbing barriers $F_{G}(0,0)$, $F_{G}\left(0, K_{G}\right)$, thus $A_{3}=A_{4}=0$, since the option to invest is worthless if the present value of future cash-flows is zero. Likewise, for $F_{G}\left(V_{G}, K_{G}\right)$, and as $K_{G}$ becomes infinitely large for any value of $V_{G}$, then the option is also worthless. To respect this condition, we need to set constant $A_{1}=0$, leaving only constant $A_{2} \neq 0$. Thus, in our case, the quadrant

\footnotetext{
${ }^{9}$ Please refer to Adkins and Paxson (2011) for more details.
} 
of interest is the second one, corresponding to the pair of roots $\left\{\beta^{+}, \eta^{-}\right\}$. The general solution for the homogeneous partial differential equation (4), given by equation (7) is then reduced and takes the following form:

$$
F_{G}\left(V_{G}, K_{G}\right)=A_{2} V_{G}^{\beta^{+}} K_{G}^{\eta^{-}}-\frac{s}{\delta_{V_{G}}} V_{G}
$$

The value matching condition implies that, when the trigger values for both $V_{G}$ and $K_{G}$ are simultaneously attained, the value of the option to invest must equal the project's expected Net Present Value. Being so:

$$
F_{G}\left(V_{G}^{*}, K_{G}^{*}\right)=A_{2} V_{G}^{*^{\beta^{+}}} K_{G}^{*^{\eta^{-}}}-\frac{s}{\delta_{V_{G}}} V_{G}^{*}=V_{G}^{*}-K_{G}^{*}
$$

As the value-matching condition supports homogeneity of degree one on both sides of the equation, we can reduce the dimensionality of the problem to only one variable, since $\beta^{+}+\eta^{-}=1$. Thus, the trigger value for $V_{G}^{*}$ will be given by the following equation: ${ }^{10}$

$$
V_{G}^{*}=\frac{\beta}{\beta-1} \frac{K_{G}^{*}}{\left(1+\frac{s}{\delta_{V_{G}}}\right)}
$$

where $\beta$ is the root of the fundamental quadratic equation (12) below, whose value exceeds one. ${ }^{11}$

$$
Q=\frac{1}{2}\left(\sigma_{V_{G}}^{2}-2 \rho_{G} \sigma_{V_{G}} \sigma_{K_{G}}+\sigma_{K_{G}}^{2}\right) \beta(\beta-1)+\left(\delta_{K_{G}}-\delta_{V_{G}}\right) \beta-\delta_{K_{G}}=0
$$

Equation (11) lead us to conclude that there is a countless pairs of government triggers, $\left\{K_{G}^{*}, V_{G}^{*}\right\}$ whose values depend on the value of the root $\beta$, on the level of social costs estimated by the government, $s$ and on the risk of return-shortfall, $\delta_{V_{G}}$. A discriminatory boundary does exist, separating the waiting region from the investing region, provided that we stipulate a set of values for $K_{G}^{*}$ or a set of values for $V_{G}^{*}$. By setting a value for one of the two triggers, we reach the value of the other trigger by merely applying equation (11) for a given level of social costs and assuming the value of $\delta_{V_{G}}$.

\footnotetext{
${ }^{10}$ Please note that, in the absence of social costs, the solution given by equation (11) is reduced to the one presented in Dixit and Pindyck (1994) for the case of two stochastic variables.

${ }^{11}$ Please refer to Dixit and Pindyck (1994) for further details.
} 
The Figure below illustrates the government discriminatory boundary, separating the waiting region from the investing region. We considered a set of pairs, $\left\{K_{G}^{*} ; V_{G}^{*}\right\}$, with $K_{G}^{*}$ ranging from 100 to 300 . The base case parameter values included in Table 1 apply.

Figure 1: the government discriminatory boundary

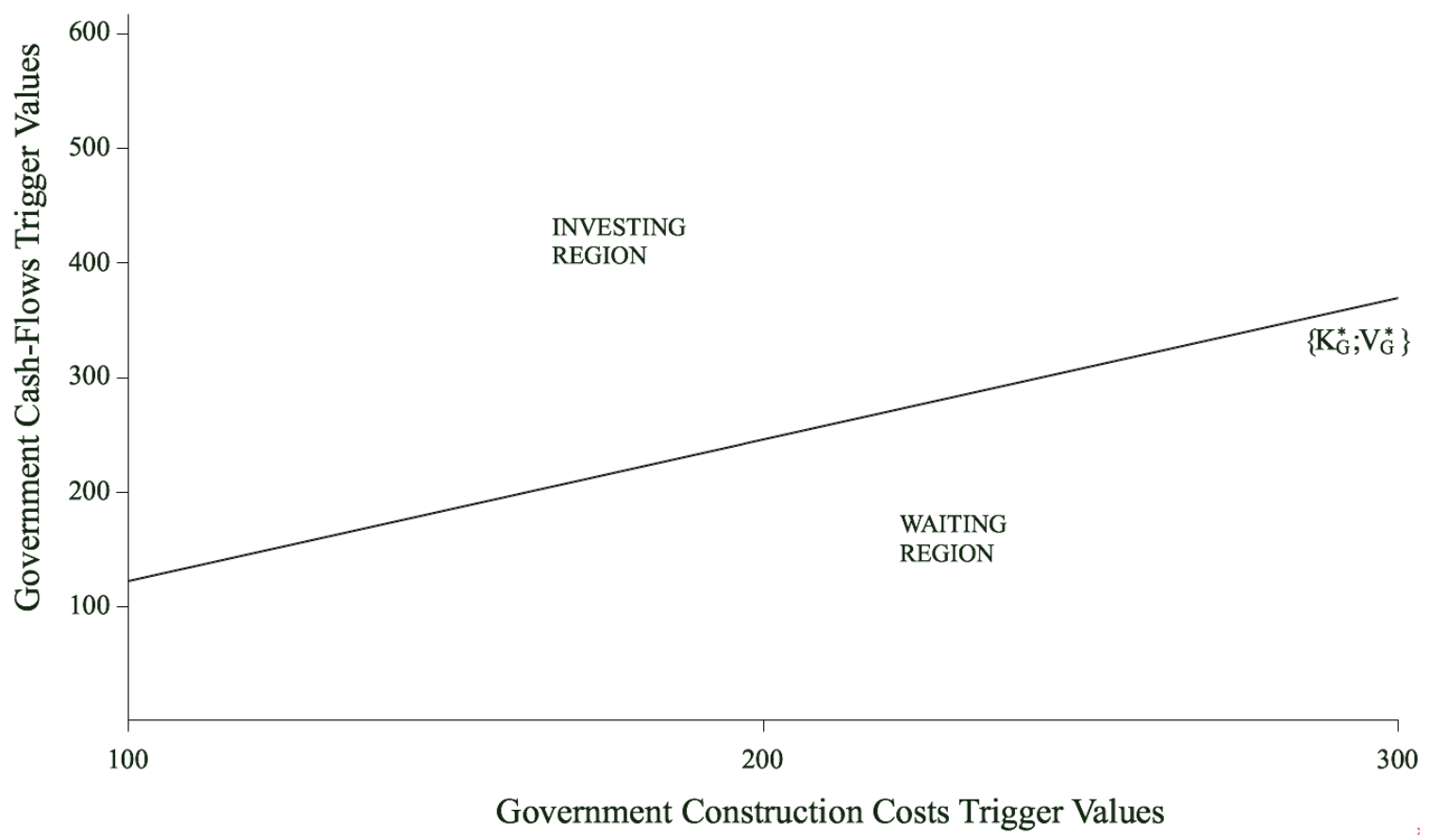

The discriminatory boundary in Figure 1 has a constant and positive slope and, thus, the relationship between the two variables is linear. An increase (decrease) in $K_{G}^{*}$ of, say, $10 \%$, will lead to an increase (decrease) of $10 \%$ in the value of the cash-flows for the investment to be triggered. The existence of this relationship means that a trade-off exists between the cash-flows trigger and the construction costs trigger. As Dixit and Pindyck (1994) stated, when one of the two triggers is affected by a (negative) positive variation, the other variable responds with a (negative) positive variation of the same dimension.

\subsubsection{The Government Expectation about the Firm Investment Decision}

We have been assuming that the private firm is more efficient than the government in constructing the project facility. Being so, let $\gamma$ denote the comparative efficiency coefficient. We can then relate the government construction costs with the expectation the government has about the private firm construction costs, applying the following equation: 


$$
K_{P}=K_{G}(1-\gamma)
$$

We now proceed to compute the trigger values of the private firm as estimated by the government. The firm may face a penalty cost, which we denote by $c$, for delaying the initiation of the project. This means that - even though flexibility concerning the timing to implement the project is present - such flexibility implies a cost, as we have stressed. Let $F_{P}\left(V_{P}, K_{P}\right)$ denote the government expectation about the value of the private firm investment opportunity. Under risk-neutrality, $F_{P}\left(V_{P}, K_{P}\right)$ must satisfy the following partial differential equation:

$$
\begin{aligned}
& \frac{1}{2} \sigma_{V_{P}}^{2} V_{P}^{2} \frac{\partial^{2} F_{P}}{\partial V_{P}^{2}}+ \frac{1}{2} \sigma_{K_{P}}^{2} K_{P}^{2} \frac{\partial^{2} F_{P}}{\partial K_{P}^{2}}+\rho_{P} \sigma_{V_{P}} \sigma_{K_{P}} V_{P} K_{P} \frac{\partial^{2} F_{P}}{\partial V_{P} \partial K_{P}}+ \\
&\left(r-\delta_{V_{P}}\right) V_{P} \frac{\partial F_{P}}{\partial V_{P}}+\left(r-\delta_{K_{P}}\right) \frac{\partial F_{P}}{\partial K_{P}}-r F_{P}-c=0
\end{aligned}
$$

Equation (14) has a non-homogeneous part, $c$ and the rest of the equation is homogeneous. We reach the general solution for the homogeneous part of the partial differential equation (14) by applying the same reasoning as in the previous case, i.e., the government investment decision. Being so, the general solution for the homogeneous part of equation (14), $F_{P}^{H}\left(V_{P}, K_{P}\right)$ takes the form:

$$
F_{P}^{H}\left(V_{P}, K_{P}\right)=A_{5} V_{P}^{\beta^{+}} K_{P}^{\eta^{+}}+A_{6} V_{P}^{\beta^{+}} K_{P}^{\eta^{-}}+A_{7} V_{P}^{\beta^{-}} K_{P}^{\eta^{+}}+A_{8} V_{P}^{\beta^{-}} K_{P}^{\eta^{-}}
$$

As in the previous case, we are only interested in the pair of roots $\left\{\beta^{+}, \eta^{-}\right\}$, which simplifies the solution given by equation (15). Hence, we reach a reduced solution, given by the following equation:

$$
F_{P}^{H}\left(V_{P}, K_{P}\right)=A_{6} V_{P}^{\beta^{+}} K_{P}^{\eta^{-}}
$$

The particular solution we propose for the non-homogeneous part, $F_{P}^{N H}$ is:

$$
F_{P}^{N H}=-\frac{c}{r}
$$


Stitching together the homogeneous and non-homogeneous solutions, we obtain the following expression that satisfies the whole partial differential equation (14):

$$
F_{P}^{H}\left(V_{P}, K_{P}\right)+F_{P}^{N H}=F_{P}\left(V_{P}, K_{P}\right)=A_{6} V_{P}^{\beta^{+}} K_{P}^{\eta^{-}}-\frac{c}{r}
$$

The value-matching condition, in these circumstances, is given by:

$$
F_{P}\left(V_{P}^{*}, K_{P}^{*}\right)=A_{6} V_{P}^{*^{\beta^{+}}} K_{P}^{*^{\eta^{-}}}-\frac{c}{r}=V_{P}^{*}-K_{P}^{*}
$$

Unfortunately, this value-matching condition does not support homogeneity of degree one on both sides, which means that $\beta^{+}+\eta^{-} \neq 1$. To overcome this problem, we follow Adkins and Paxson (2011) quasi-analytical solution by constructing a set of three simultaneous equations. The first equation is the elliptical equation (20) below, which is equivalent to equation (8):

$$
\begin{aligned}
Q(\beta, \eta)= & \frac{1}{2} \sigma_{V_{P}}^{2} \beta(\beta-1)+\frac{1}{2} \sigma_{K_{P}}^{2} \eta(\eta-1)+ \\
& \rho \sigma_{V_{P}} \sigma_{K_{P}} \beta \eta+\left(r-\delta_{V_{P}}\right) \beta+\left(r-\delta_{K_{P}}\right) \eta-r=0
\end{aligned}
$$

The other two equations are the two smooth-pasting conditions derived from the valuematching condition, given by equation (19). The first smooth-pasting condition is the first-order derivative of the value-matching condition, in respect to $V_{P}^{*}$. After applying some rules of calculus, we obtain the first smooth-pasting condition, which is given by the following equation:

$$
\beta^{+}\left(V_{P}^{*}-K_{P}^{*}+\frac{c}{r}\right)=V_{P}^{*}
$$

The second smooth-pasting condition is the first-order derivative of the value matching condition, given by equation (19), in respect to $K_{P}^{*}$. Likewise, after applying some rules of calculus, we reach the second smooth-pasting condition, given by equation (22) below:

$$
\eta^{-}\left(V_{P}^{*}-K_{P}^{*}+\frac{c}{r}\right)=-K_{P}^{*}
$$


Firstly, we will consider that $c=0$, i.e., we will derive the private firm cash-flows trigger as if no legal penalty was enforced. Being so, as in the case of Adkins and Paxson (2011), we face the existence of four unknowns: $V_{P}^{*}, K_{P}^{*}, \beta^{+}, \eta^{-}$and only three equations are available. We will use a set of simultaneous equations, as Adkins and Paxson (2011) did to determine the four uncertains. The set of equations is formed by equations (20), (21) and (22), enabling us to reach new values for $V_{P}^{*}, \beta^{+}, \eta^{+}$, after perturbing $K_{P}^{*}$. Thus, by applying this procedure, we determine the firm cash-flows trigger, for a given $K_{P}^{*}$, as if no penalty was enforced. We will designate, from now on, this trigger as $V_{P}^{+}$. Hence, $V_{P}^{+}$ represents the private firm trigger that needs to be moved downwards in order to perfectly meet the government cash-flows trigger, $V_{G}^{*}{ }^{12}$ Secondly, we will use the same set of simultaneous equations with the purpose of determining the exact value for $c$ that moves $V_{P}^{+}$downwards to perfectly meet $V_{G}^{*}$. The value of $c$ that perfectly moves $V_{P}^{+}$downwards in order to meet $V_{G}^{*}$ is the optimal value for the contractual penalty. Therefore, the optimal contractual penalty is the one that makes $V_{P}^{*}=V_{G}^{*}$ for a given $K_{P}^{*}$ or, which is the same, the one that perfectly aligns both cash-flows triggers. We designate the optimal value for the contractual penalty as $c^{*}$.

\subsubsection{Determining the Optimal Value for the Contractual Penalty}

The following table exhibits a set of representative values for $K_{G}^{*}, V_{G}^{*}, K_{P}^{*}, V_{P}^{+}, c^{*}$ and $V_{P}^{*}$. The values were obtained by solving the set of simultaneous equations formed by equations (20), (21) and (22) and applying the procedure previously described. We consider three possible project dimensions, given by $K_{G}^{*}=100, K_{G}^{*}=200$ and $K_{G}^{*}=300$.

Table 2: representative values for the government triggers, the private firm triggers and the optimal contractual penalty, for three project dimensions

(for: $\left.\sigma_{V_{G}}=\sigma_{V_{P}}=0.15 ; \sigma_{K_{G}}=\sigma_{K_{P}}=0.10 ; \delta_{V_{G}}=\delta_{V_{P}}=0.03 ; \delta_{K_{G}}=\delta_{K_{P}}=0.03 ; \rho_{G}=\rho_{P}=0 ; r=0.05 ; s=0.02 ; \gamma=0.2\right)$
\begin{tabular}{|l||l||l||l||l||l||l|l|l|}
\hline$K_{G}^{*}$ & $K_{P}^{*}$ & $V_{G}^{*}$ & $V_{P}^{+}$ & $c^{*}$ & $V_{P}^{*}$ & $c * / K_{G}^{*}$ & $c * / K_{P}^{*}$ \\
\hline \hline 100 & 80 & 123 & 164 & 0.9611 & 123 & 0.0096 & 0.012 \\
\hline \hline 200 & 160 & 247 & 329 & 1.9222 & 247 & 0.0096 & 0.012 \\
\hline \hline 300 & 240 & 370 & 493 & 2.8833 & 370 & 0.0096 & 0.012 \\
\hline
\end{tabular}

Results in Table 2 clearly show that the level of the optimal contractual penalty, $c^{*}$ is proportional to the level of $K_{G}^{*}$ and, consequently, also proportional to the level of $K_{P}^{*}$.

\footnotetext{
${ }^{12} \mathrm{We}$ are assuming that $V_{P}^{+}$is greater than $V_{G}^{*}$, otherwise there would be no need for a legal penalty to be included in the contract, as we observed.
} 
This means that no scale-effect is present in the model: an increase (decrease) in the construction costs trigger will lead to an increase (decrease) in the value of the optimal legal penalty of the same magnitude. This proportionality feature allows us to determine the level of the optimal contractual penalty "per unit" of the private firm's expected construction costs which, according to the inputs considered, equals approximately, 0.012.

The following figure shows the impact of the optimal contractual penalty on the private firm discriminatory boundary. In Figure 2, the government discriminatory boundary, formed by pairs $\left\{K_{G}^{*} ; V_{G}^{*}\right\}$ is presented again. The private firm discriminatory boundary before considering the impact of the contractual penalty, formed by pairs $\left\{K_{P}^{+} ; V_{P}^{+}\right\}$ and the private firm discriminatory boundary, formed by pairs $\left\{K_{P}^{*} ; V_{P}^{*}\right\}$ - which results from considering the impact of the optimal contractual penalty "per unit" of the private firm expected construction costs - are both designed, for the three project dimensions considered.

Figure 2: the impact of the optimal contractual penalty on the private firm discriminatory boundary

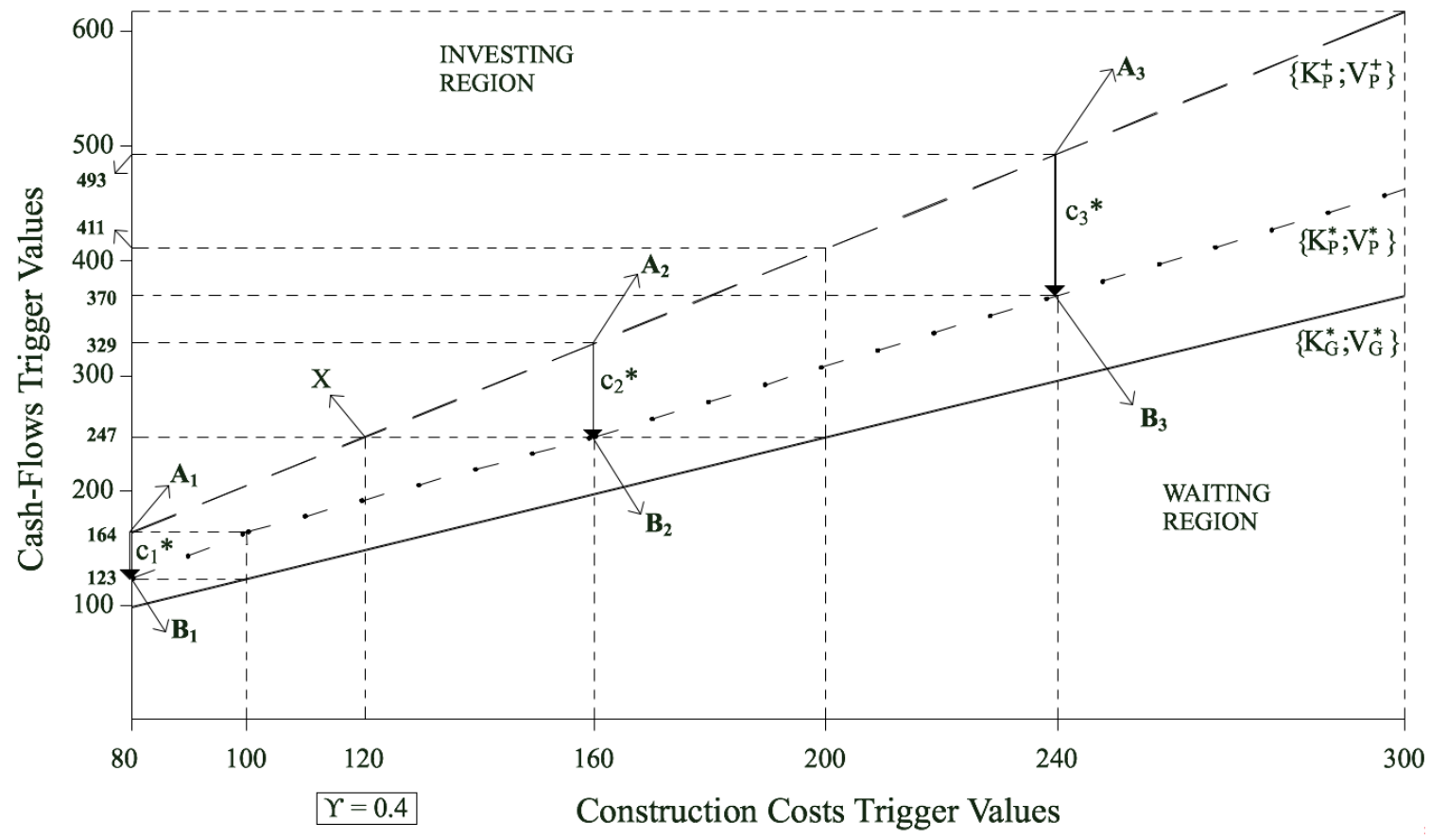

Figure 2 above shows the private firm pair of triggers before considering the impact of the optimal legal penalty, for the three dimensions. If no legal penalty is enforced in the contract, the government would expect the private firm to invest in the pair of triggers represented by points $A_{1}=\{80 ; 164\}, A_{2}=\{160 ; 329\}$ and $A_{3}=\{240 ; 493\}$, each corresponding to one of the three project dimensions we are considering and assuming that 
the comparative efficiency is $\gamma=0.2$. Thus, by solving the system of simultaneous equations composed by equations (4.20), (4.21) and (4.22), we have reached the three points $B_{1}=\{80 ; 123\}, A_{2}=\{160 ; 247\}$ and $A_{3}=\{240 ; 370\}$. By joining these three points, we obtain another discriminatory boundary: the private firm discriminatory boundary after considering the impact of the optimal contractual penalty, formed by pairs $\left\{K_{P}^{*} ; V_{P}^{*}\right\}$. In fact, points $A_{1}, A_{2}$ and $A_{3}$ are three of a countless set of points representing a countless set of pairs, $\left\{K_{P}^{*} ; V_{P}^{*}\right\}$ which define the private firm discriminatory boundary after considering the impact of the contractual penalty. Figure 2 also clearly shows that the private firm discriminatory boundary does not match the government discriminatory boundary. In fact, as we have argued, the optimal penalty for each project dimension, $c_{1}^{*}, c_{2}^{*}$ and $c_{3}^{*}$ is the one that moves the private firm cash-flows trigger downwards in order to perfectly meet the government cash-flows trigger. This is exactly the effect that each of the optimal values for the contractual penalty produce and such effect is represented in Figure 2 by three arrows, one for each project dimension. It is visible that the greater the project dimension the greater the size of the corresponding arrow, hence reflecting that a higher contractual penalty is needed as the project assumes greater dimensions. The private firm discriminatory boundary, formed by pairs $\left\{K_{P}^{*} ; V_{P}^{*}\right\}$ is then situated between the private firm discriminatory boundary before considering the impact of the contractual penalty, formed by pairs $\left\{K_{P}^{+} ; V_{P}^{+}\right\}$and the government discriminatory boundary, formed by pairs $\left\{K_{G}^{*} ; V_{G}^{*}\right\} .{ }^{13}$

Figure 2 also includes a specific point, which we designate as $X$. This point is situated where the private firm discriminatory boundary, after considering the impact of the optimal legal penalty (the one composed by pairs $\left\{K_{P}^{*} ; V_{P}^{*}\right\}$ ), intersects the line for the government cash-flows trigger on the second dimension, i.e., $V_{G}^{*}=247$. To this project dimension, the government cash-flows trigger and private firm cash-flows trigger are both equal to 247 and, to that cash-flows trigger value, corresponds a private firm construction costs trigger of $K_{P}^{*}=120$. Hence, considering the second dimension, given by $K_{G}^{*}=200$, the private firm construction costs trigger, $K_{P}^{*}=120$ when the comparative efficiency factor, $\gamma=0.4$. This means that, for this project dimension, if the comparative efficiency factor is equal or greater than 0.4 , there is no need to include a legal penalty in the contract form because the efficiency factor, for a level of social costs equal to 0.02 , is strong enough to move the private firm cash-flows trigger downwards in order to perfectly meet the government cash-flows trigger.

\footnotetext{
${ }^{13}$ The private firm discriminatory boundary, after considering the impact of the optimal legal penalty, will only match the government discriminatory boundary if both entities were equally efficient, i.e., if $\gamma=0$.
} 


\subsection{Sensitivity Analysis}

\subsubsection{The Impact of the Level of Social Costs on the Optimal Contractual Penalty}

Table 3 includes a set of values for the level of social costs and their impact on the government cash-flows trigger and on the optimal contractual penalty, assuming the project dimension given by $K_{G}^{*}=200$.

Table 3: sensitivity analysis: the impact of the level of social costs on the optimal contractual penalty

(for: $\sigma_{V_{G}=\sigma_{V_{P}}=} 0.15 ; \sigma_{K_{G}}=\sigma_{K_{P}}=0.10 ; \delta_{V_{G}}=\delta_{V_{P}}=0.03 ; \delta_{K_{G}}=\delta_{K_{P}}=0.03 ; \rho_{G}=\rho_{P}=0 ; r=0.05 ; \gamma=0.2$ )
\begin{tabular}{|c||c||c||c||c|c|c|}
\hline$K_{G}^{*}$ & $K_{P}^{*}$ & $s$ & $V_{G}^{*}$ & $c *$ & $V_{P}^{+}$ & $V_{P}^{*}$ \\
\hline \hline 200 & 160 & 0.00 & 411 & $\mathbf{0 . 0 0 0 0}$ & 329 & 411 \\
\hline \hline 200 & 160 & 0.01 & 308 & $\mathbf{0 . 4 7 3 2}$ & 329 & 308 \\
\hline \hline 200 & 160 & 0.02 & 247 & $\mathbf{1 . 9 2 2 2}$ & 329 & 247 \\
\hline \hline 200 & 160 & 0.03 & 206 & $\mathbf{2 . 9 2 3 5}$ & 329 & 206 \\
\hline \hline 200 & 160 & 0.04 & 176 & $\mathbf{3 . 6 6 6 1}$ & 329 & 176 \\
\hline \hline 200 & 160 & 0.05 & 154 & $\mathbf{4 . 2 4 4 3}$ & 329 & 154 \\
\hline
\end{tabular}

Assuming $s=0$, then there is no need for enforcing a legal penalty, since the government cash-flows trigger $\left(V_{G}^{*}=411\right)$ is placed above the private firm cash-flows trigger, before considering the effect of any penalty $\left(V_{P}^{+}=329\right)$. For values of $s$ greater than zero, the higher the level of social costs the more below the government cash-flows trigger is situated, which means that the distance between the private firm cash-flows trigger and the government cash-flows trigger becomes greater. As a consequence, higher levels for the contractual penalty are needed to move the private firm cash-flows trigger downwards and align it with the government cash-flows trigger.

\subsubsection{The Impact of the Efficiency Factor on the Optimal Contractual Penalty}

Table 4 includes a set of different values for the comparative efficiency factor and their impact on the optimal contractual penalty, assuming that the project dimension is given by $K_{G}^{*}=200$. 
Table 4: sensitivity analysis: the impact of the efficiency factor on the optimal contractual penalty

$$
\text { (for: } \sigma_{V_{G}}=\sigma_{V_{P}}=0.15 ; \sigma_{K_{G}}=\sigma_{K_{P}}=0.10 ; \delta_{V_{G}}=\delta_{V_{P}}=0.03 ; \delta_{K_{G}}=\delta_{K_{P}}=0.03 ; \rho_{G}=\rho_{P}=0 ; r=0.05 ; s=0.02 \text { ) }
$$

\begin{tabular}{|c||c||c||c||c||c||c|}
\hline$\gamma$ & $K_{G}^{*}$ & $K_{P}^{*}$ & $V_{G}^{*}$ & $c *$ & $V_{P}^{+}$ & $V_{P}^{*}$ \\
\hline \hline 0.0 & 200 & 200 & 247 & $\mathbf{3 . 9 1 1 0}$ & 411 & 247 \\
\hline \hline 0.1 & 200 & 180 & 247 & $\mathbf{2 . 9 0 8 7}$ & 370 & 247 \\
\hline \hline 0.2 & 200 & 160 & 247 & $\mathbf{1 . 9 2 2 2}$ & 329 & 247 \\
\hline \hline 0.3 & 200 & 140 & 247 & $\mathbf{0 . 9 5 2 3}$ & 288 & 247 \\
\hline \hline $\mathbf{0 . 4}$ & $\mathbf{2 0 0}$ & $\mathbf{1 2 0}$ & $\mathbf{2 4 7}$ & $\mathbf{0 . 0 0 0 0}$ & $\mathbf{2 4 7}$ & $\mathbf{2 4 7}$ \\
\hline \hline 0.5 & 200 & 100 & 247 & $\mathbf{0 . 0 0 0 0}$ & 206 & 247 \\
\hline
\end{tabular}

Results included in Table 4 demonstrate that higher efficiency factors lead to lower triggers for the private firm construction costs which, in turn, produce lower values for the corresponding cash-flows triggers. Consequently, as the comparative efficiency factor, $\gamma$ increases, the optimal contractual penalty, $c^{*}$, decreases, since both triggers are closer to each other, until a value is reached for the comparative efficiency which, by itself, is strong enough to align the two cash-flows triggers. We thus conclude that there is a value for the efficiency factor above which there is no need to include a contractual penalty in the contract form. Also, as we observed, Figure 2 above includes the point $X$ - whose coordinates are $\{120 ; 247\}$ - which corresponds to this level of comparative efficiency and is situated where the private firm discriminatory boundary, before considering the effect of the contractual penalty, intersects the government discriminatory boundary, for the project dimension given by $K_{G}^{*}=200$. When the efficiency factor level is above 0.4 , the private firm cash-flows trigger will be placed below the government trigger, meaning that there is no need to include a legal penalty in the contract, since the government's purpose is already accomplished. In such cases, and according to our numerical example, the optimal contractual penalty will, therefore, equal zero.

We have concluded that a legal penalty in the contract is only justified for levels of comparative efficiency lower than 0.4 , considering a level of social costs of 0.02 . We can derive an analytical solution to obtain the level below which the inclusion of a legal penalty in the contract form is justified. Let $\bar{\gamma}$ denote the level of comparative efficiency that align both cash-flows triggers: this is the level below which a legal penalty should be enforced. Being so, $\bar{\gamma}$ will be given by the following equation: 


$$
\bar{\gamma}=\frac{s}{s+\delta_{V_{P}}}
$$

As we are departing from equal values to the parameters that influence the value of $\beta$, both for the government and the private firm, we have reached a solution for $\bar{\gamma}$ which is independent of $\beta$ and merely depends on the private firm cash-flows rate of returnshortfall, $\delta_{V_{P}}$ and the level of social costs, $s$. The higher the value of $s$, the higher the value for $\bar{\gamma}$, regardless of the estimated level for the efficiency factor. However, if for an estimated level of comparative efficiency and given a specific level of social costs, the private firm cash-flows trigger has not meet the government cash-flows trigger (meaning that the government's purpose has not been accomplished), then a legal penalty should be enforced in order to perfectly align the two cash-flows triggers.

\subsubsection{The Combined Impact of the Level of Social Costs and the Level of the Effi- ciency Factor on the Optimal Contractual Penalty}

We will now demonstrate how the level of social costs, combined with the level of the comparative efficiency, affect the optimal contractual penalty. As shown in Table 3, the greater the level of social costs the lower the government cash-flows trigger. The government cash-flows trigger is thus shifted downwards due to the existence of social costs, pressuring the government to invest sooner. However, we now have to confront the government cash-flows trigger, affected by a set of different levels for the social costs, with the private firm cash-flows trigger, affected by different levels of comparative efficiency. We emphasize that the optimal contractual penalty is the one that moves the private firm cash-flows trigger downwards with the purpose of perfectly meeting the government cashflows trigger, for any dimension the project may assume. 
Table 5: sensitivity analysis: the combined impact of the level of social costs and the level of the efficiency factor on the optimal contractual penalty

\begin{tabular}{|c|c|c|c|c|c|}
\hline & $s=0.01$ & $s=0.02$ & $s=0.03$ & $s=0.04$ & $s=0.05$ \\
\hline$\gamma=0.1$ & 1.4311 & 2.9087 & 3.9359 & 4.7014 & 5.2996 \\
\hline$\gamma=0.2$ & 0.4734 & 1.9222 & 2.9235 & 3.6661 & 4.2443 \\
\hline$\gamma=0.3$ & 0.0000 & 0.9523 & 1.9290 & 2.6494 & 3.2078 \\
\hline$\gamma=0.4$ & 0.000 & 0.0000 & 0.0000 & 1.6535 & 2.1926 \\
\hline$\gamma=0.5$ & 0.000 & 0.0000 & 0.000 & 0.6802 & 1.2013 \\
\hline
\end{tabular}

The values included in Table 5 are the optimal penalty values that result from considering combinations for the level of social costs and for the level of the efficiency factor. The results clearly illustrate what we have been arguing: the greater the level of social costs the higher the value of the optimal legal penalty and, the higher the efficiency factor, the lower the value of the optimal penalty. However, when the comparative efficiency factor is equal to or higher than 0.4 and the level of social costs is equal to or lower than 0.03 , there is no need to impose a legal penalty in the contract form because the combination of the two factors is strong enough to align the two cash-flows triggers. The same also happens when $\gamma=0.3$ and $s=0.01$. This is the reason why, in such cases, the optimal contractual penalty included in Table 5 is zero.

\subsubsection{The Impact of Variations in the Correlation Coefficients on the Optimal Con- tractual Penalty}

We have been assuming that the correlation coefficient, $\rho$ is zero and, hence, all calculations were made considering the absence of correlation between the facility construction costs and the present value of cash-flows to be generated from subsequent operations. Table 6 includes the results of the impact on the optimal contractual penalty caused by variations in both correlation coefficients, $\rho_{G}$ and $\rho_{P}$, assuming $\gamma=0.2$ and $s=0.02$. We should stress that any change in $\rho_{G}$ will cause the roots that are extracted from equation (8) to change and, thus, $V_{G}^{*}$ will also change. The impact on $V_{P}^{+}$is also presented. We set $K_{G}^{*}$ to 200 and the conclusions are equivalent for any other level of $K_{G}^{*}$, since the results included in Table 2 demonstrate the existence of proportionality between this trigger and 
the optimal level for the contractual penalty, $c^{*} .{ }^{14}$

Table 6: the impact of variations in the correlation coefficients on the optimal contractual penalty

$$
\text { (for: } \sigma_{V_{G}}=\sigma_{V_{P}}=0.15 ; \sigma_{K_{G}}=\sigma_{K_{P}}=0.10 ; \delta_{V_{G}}=\delta_{V_{P}}=0.03 ; \delta_{K_{G}}=\delta_{K_{P}}=0.03 ; r=0.05 ; s=0.02 ; \gamma=0.2 \text { ) }
$$

\begin{tabular}{|c||c||c||c||c||c|}
\hline$\left(\rho_{G} ; \rho_{P}\right)$ & $\mathbf{( - 1 . 0} ;-\mathbf{1 . 0})$ & $\mathbf{( - 0 . 5} ;-\mathbf{0 . 5})$ & $\mathbf{( 0 . 0} ; \mathbf{0 . 0})$ & $\mathbf{( 0 . 5} ; \mathbf{0 . 5})$ & $\mathbf{( 1 . 0 ; 1 . 0 )}$ \\
\hline \hline$K_{G}^{*}$ & 200 & 200 & 200 & 200 & 200 \\
\hline \hline$V_{G}^{*}$ & 320 & 284 & 247 & 205 & 147 \\
\hline \hline$V_{P}^{+}$ & 427 & 379 & 329 & 273 & 196 \\
\hline \hline$V_{P}^{*}$ & 320 & 284 & 247 & 205 & 147 \\
\hline \hline$c^{*}$ & $\mathbf{2 . 3 2 1 3}$ & $\mathbf{2 . 1 2 9 5}$ & $\mathbf{1 . 9 2 2 2}$ & $\mathbf{1 . 6 7 9 1}$ & $\mathbf{1 . 1 9 6 7}$ \\
\hline
\end{tabular}

Results in Table 6 show that one should expect that, as the correlation coefficients increase, from $(-1.0 ;-1.0)$ to $(1.0 ; 1.0)$, the value of the optimal legal penalty would decrease, since stronger positive (or less negative) correlations lead to lower cash-flows trigger values, both for the government and the private firm. It is expected that increasing positive (or less decreasing negative) correlations would result in lower cash-flows triggers for both entities. If, say, construction costs rise 20 and $\rho=0.5$, thus the cash-flows will, expectedly, rise 10, which means that the cash-flows trigger will be lower. If, for the same variation in the construction costs, the cash-flows rise more than 10 (which means that $\rho>0.5$ ), then one would expect that the cash-flows trigger value would be even lower than in the previous example. Triggers will, therefore, be closer to each other as positive (or less negative) correlations become greater and the differences between the triggers become smaller. And, since the difference between the triggers will be smaller, one would expect that a lower value for the contractual penalty will be sufficient to perfectly align them. On the contrary, higher negative correlations (or lower positive correlations) will, expectedly, result in greater differences between the private firm cash-flows trigger - in the event that no penalty is enforced - and the government cash-flows trigger, meaning that, in these circumstances, a greater value for the legal penalty will be needed in order to move the firm cash-flows trigger downwards and perfectly align it with the government cash-flows trigger, for each value the correlation coefficient may assume.

\footnotetext{
${ }^{14}$ In order to confirm the existence of this proportionality, we set $K_{G}^{*}$ to 100 and reached optimal penalty values, for all levels of $\rho$, half as great as the ones included in Table 6. These results demonstrate the existence of proportionality between $K_{G}^{*}$ and $c^{*}$, as the results included in Table 2 demonstrate.
} 


\subsubsection{The Impact of Changes in the Standard Deviations on the Optimal Contrac- tual Penalty}

Table 7 illustrates how the consideration of changes in both standard deviations affect the optimal contractual penalty value. We consider variations in $\left(\sigma_{K} ; \sigma_{V}\right)$ ranging from $(0.05 ; 0.05)$ to $(0.30 ; 0.30)$. We should stress that any change considered in the volatility parameters will cause the roots that are extracted from equation (8) to change and, thus, $V_{G}^{*}$ will also change.

Table 7: the impact of changes in the volatility levels on the optimal contractual penalty

(for: $\delta_{V_{G}}=\delta_{V_{P}}=0.03 ; \delta_{K_{G}}=\delta_{K_{P}}=0.03 ; r=0.05 ; s=0.02 ; \gamma=0.2$ )

\begin{tabular}{|c||c||c||c||c||c||c|}
\hline$\left(\sigma_{k} ; \sigma_{V}\right)$ & $\mathbf{( 0 . 0 5} ; \mathbf{0 . 0 5})$ & $\mathbf{( 0 . 1 0 ; ~ 0 . 1 0 )}$ & $\mathbf{( 0 . 1 5 ; ~ 0 . 1 5 )}$ & $\mathbf{( 0 . 2 0 ; ~ 0 . 2 0 )}$ & $\mathbf{( 0 . 2 5 ; ~ 0 . 2 5 ) ~}$ & $\mathbf{( 0 . 3 0 ; ~ 0 . 3 0 )}$ \\
\hline \hline$V_{G}^{*}$ & 160 & 212 & 278 & 360 & 459 & 575 \\
\hline \hline$V_{P}^{+}$ & 213 & 283 & 371 & 480 & 611 & 767 \\
\hline \hline$c^{*}$ & $\mathbf{1 . 7 8 8 9}$ & $\mathbf{2 . 0 0 4 4}$ & $\mathbf{2 . 2 3 5 0}$ & $\mathbf{2 . 4 5 7 9}$ & $\mathbf{2 . 6 6 3 1}$ & $\mathbf{2 . 8 4 5 4}$ \\
\hline \hline$V_{P}^{*}$ & 160 & 212 & 278 & 360 & 459 & 575 \\
\hline
\end{tabular}

Results included in Table 7 show that higher volatility levels lead to higher values for both the government cash-flows trigger and the private firm cash-flows trigger, as expected. However, the distance between the private firm cash-flows trigger before considering the effect of the contractual penalty, $V_{P}^{+}$and the government cash-flows trigger, $V_{G}^{*}$ is greater as the volatility level increases. This increasing difference between the two cash-flows triggers is explained by the combined effect that the efficiency factor and the level of social costs produce in the private firm cash-flows trigger and in the government cashflows trigger, respectively. Assuming that $\gamma=0.2$ and $s=0.02$, the effect of the level of social costs in moving the government cash-flows trigger downwards is stronger than the effect caused by the efficiency factor in placing the private firm cash-flows trigger more below. This greater distance between the two triggers results in higher values for $c^{*}$, since the effect produced by the legal penalty needs to be stronger, in order to move the private firm cash-flows trigger downwards and perfectly meet the government cash-flows trigger. $^{15}$

\footnotetext{
${ }^{15}$ We have determined the triggers values for the cash-flows of both entities, firstly not considering the effect caused by the level of the efficiency factor and, secondly not considering the effect caused by the level of social costs. The difference between the two cash-flows triggers is greater in the first case, which demonstrates that the effect produced by the level of social costs is stronger, for the combinations of standard deviations that we have considered.
} 


\section{The Effects, to the Government, of a Including a Non-Optimal Value for the Legal Penalty in the Contract}

The model described proposes a method to determine the optimal level for the contractual penalty, from the government perspective. Based on its own estimates about the facility construction costs and the value of cash-flows to be generated from running the subsequent operations, and estimating the level of social costs and the comparative efficiency factor, the government is able to reach the value for the optimal contractual penalty "per unit" of the private firm's expected cost. This optimal contractual penalty moves the private firm cash-flows trigger downwards in order to meet the government cash-flows trigger. However, as we are considering the government facility construction costs to be stochastic, one may legitimately ask which value for the government construction costs should the government consider for the purpose of determining the optimal penalty to be included in the contract form, in the day the optimal contractual penalty needs to be determined. Since any rational agent makes decisions based on the best information he or she has in the specific moment the decisions need to be taken, we can conclude that the estimated value for the construction costs the government has computed in that same moment will be the value the government should use for the purpose of determining the optimal contractual penalty. However, since the government construction costs, $K_{G}$ behave stochastically, their value might be different the day after the day the value for the contractual penalty was determined. If such occurs, the value of the legal penalty determined and included in the contract form the day before will no longer be optimal. However, since the government needs to make a decision, the optimal value for the contractual penalty, on that day, is determined by the government, based on the expected construction costs estimated on that same day, and included in the contract form. Sometime after, a competitive bid takes place. All bidders have access to this crucial information since the contractual rules are included in the bid documents provided to all the participants. Bidders prepare their proposals taking into account the presence of this contractual penalty and define their bid prices accordingly. One of the bidders is selected and invited to sign the contract and, consequently, to invest in executing the project facility and run the subsequent activities.

Yet, one may consider that the value of the legal penalty included in the contract form is not optimal - not only due to the fact the government construction costs behave stochastically, as we just mentioned - but also because the government might have inaccurately estimated the selected bidder comparative efficiency. In fact, it is possible that the government has determined the value of the contractual penalty assuming a comparative efficiency factor which is different from the selected bidder's real comparative efficiency. Being so, we should examine the effects that overestimating or underestimating the effi- 
ciency factor will produce, from the government's perspective. For this purpose, we need to present the value of the selected bidder investment opportunity.

Let $F_{B}\left(V_{B}, K_{B}\right)$ denote the value of the selected bidder option to invest in a project where a legal penalty will be enforced in the case the selected firm does not implement the project immediately. $V_{B}$ designates the present value of the cash-flows the selected bidder will generate by running the activities and $K_{B}$ designates the selected bidder facility construction costs. Considering the same assumptions we have considered when we derived $F_{P}\left(V_{P}, K_{P}\right)$, i.e., the government expectation about the private firm decision to invest, and applying the same procedure, we then reach the boundary that separates the selected bidder's waiting and investing regions. ${ }^{16}$

Similarly, the value of the investment opportunity for the selected bidder is given by:

$$
F_{B}\left(V_{B}, K_{B}\right)=\left\{\begin{array}{rrr}
\left(V_{B}^{*}-K_{B}^{*}+\frac{c}{r}\right)\left(\frac{V_{B}}{V_{B}^{*}}\right)^{\beta^{+}}\left(\frac{K_{B}}{K_{B}^{*}}\right)^{\eta^{-}-\frac{c}{r} ; \text { if }} & \left\{K_{B}, V_{B}\right\}<\left\{K_{B}^{*}, V_{B}^{*}\right\} \\
V_{B}-K_{B} & ; \text { if } & \left\{K_{B}, V_{B}\right\} \geq\left\{K_{B}^{*}, V_{B}^{*}\right\}
\end{array}\right.
$$

We will present each of the two non-optimal scenarios separately, i.e., first we discuss the scenario where the government overestimated the selected bidder comparative efficiency and, after, the scenario where the selected bidder efficiency factor is greater than the government expected. Again, since the efficiency factor plays a crucial role in determining the optimal value for the legal penalty, any difference that may occur between the efficiency factor estimated by the government and the selected bidder's real comparative efficiency will necessarily mean that the value of the legal penalty included in the contract is not optimal. As we will demonstrate, overestimating (underestimating) the selected bidder comparative efficiency factor will lead to the inclusion of a below-optimal (above-optimal) value for the legal penalty in the contract form.

\subsection{The Effects of Including a Below-Optimal Penalty Value in the Contract}

Figure 3 illustrates the effects of overestimating the selected bidder comparative efficiency. We assume that the government estimated the selected bidder comparative efficiency as being $\gamma=0.2$, and we will consider that the selected bidder efficiency factor is, in fact, $\gamma=0.1$. We will also consider that the project dimension is given by $K_{G}^{*}=200$. Figure 3 shows the effects caused by overestimating the efficiency factor and the corresponding impact on the optimal contractual penalty.

\footnotetext{
${ }^{16}$ Please refer to the Appendix for further details.
} 
Figure 3: the impact of overestimating the comparative efficiency on the optimal contractual penalty

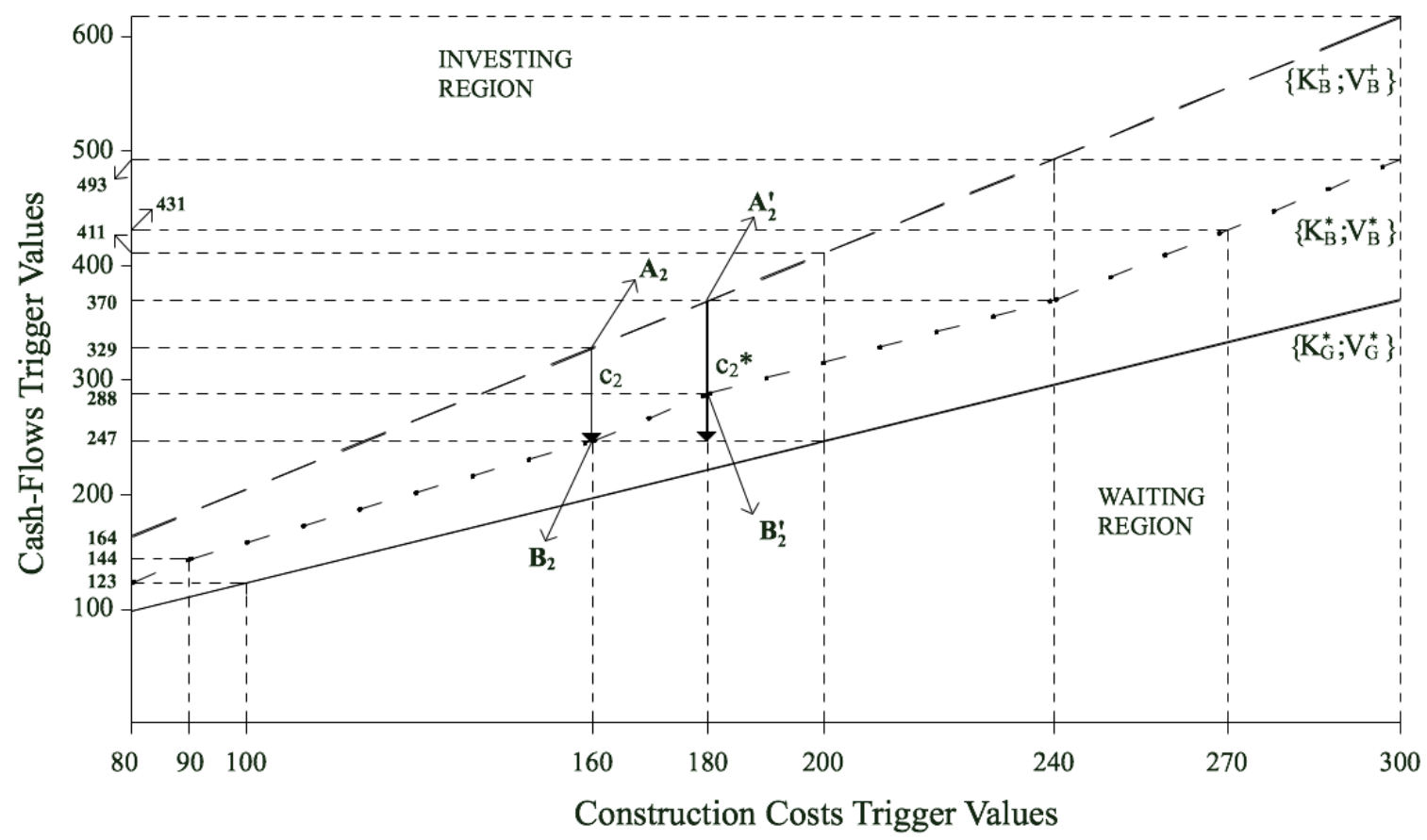

In Figure 3, point $A_{2}$ has the coordinates that correspond to the selected bidder pair of triggers before considering the effect of the contractual penalty, assuming the efficiency factor estimated by the government, i.e, $\left\{K_{B}^{+} ; V_{B}^{+}\right\}=\{160 ; 329\}$, whereas point $B_{2}$ graphically represents the selected bidder pair of triggers, $\left\{K_{B}^{*} ; V_{B}^{*}\right\}=\{160 ; 329\}$ after considering the impact of the legal penalty enforced in the contract, $c_{2}=1.9222$. In these circumstances, the government would expect the value of legal penalty included in the contract form, $c_{2}$ to be sufficiently strong in moving the selected bidder cash-flows trigger downwards, from $V_{B}^{+}=329$ to $V_{B}^{*}=247$ and, thus, perfectly meet the government cash-flows trigger, $V_{G}^{*}=247$. By overestimating the efficiency factor, the government has not succeeded in reaching such purpose. The government was expecting the selected bidder to trigger the investment in $\left\{K_{B}^{*} ; V_{B}^{*}\right\}=\{160 ; 247\}$, represented by point $B_{2}$, as the result of enforcing the contractual penalty, $c_{2}=1.9222$. If no penalty was enforced, the selected bidder would invest in point $A_{2}^{\prime}$, whose coordinates are $\left\{K_{B}^{+} ; V_{B}^{+}\right\}=\{180 ; 370\}$. By enforcing the contractual penalty $c_{2}=1.9222$ when the selected bidder comparative efficiency is $\gamma=0.1$, the government is leading the selected bidder to invest in point $B_{2}^{\prime}$, whose coordinates are $\left\{K_{B}^{*} ; V_{B}^{*}\right\}=\{180 ; 288\}$. In fact, the selected bidder construction costs trigger, considering his or her real comparative efficiency, is $K_{B}^{*}=180$, and the corresponding cash-flows trigger is $V_{B}^{*}=288 .{ }^{17}$ Thus, by imposing the contractual penalty,

\footnotetext{
${ }^{17}$ For a given value of the selected bidder construction costs trigger, the corresponding cash-flows trigger
} 
$c_{2}=1.9222$, the government has caused the selected bidder cash-flows trigger to move from $V_{B}^{+}=370$ to $V_{B}^{*}=288$. Hence, the government's purpose of moving the selected firm cash-flows trigger downwards to perfectly meet the government cash-flows trigger has not been accomplished, since the selected bidder cash-flows trigger is higher than the government cash-flows trigger. This means that a greater penalty value is needed to move further downwards0the selected bidder cash-flows trigger. In Figure 3, the optimal contractual penalty is given by $c_{2}^{*}$ and is clearly visible that the line segment reflecting the impact of the optimal contractual penalty, $c_{2}^{*}$ is bigger than the line segment that reflects the impact caused by the value of the legal penalty actually included in the contract, $c_{2}=1.9222$. This fact graphically illustrates that overestimating the comparative efficiency factor leads to the definition of a below-optimal value for the contractual penalty.

Table 8 includes a set of representative values aiming to demonstrate the effects, to government, of including a below-optimal contractual penalty in the contract form. We again assume that the project dimension is given by $K_{G}^{*}=200$ and we also consider that the pair of observed values in the market, at time $t$, for the selected bidder construction costs trigger and the corresponding cash-flows trigger, is $\left\{K_{B_{t}} ; V_{B_{t}}\right\}=\{220 ; 180\}$. We are, therefore, considering the case where, at time $t$, the selected bidder decision to invest is situated in the waiting region.

Table 8: the effects, to the government, of overestimating the comparative efficiency

\begin{tabular}{|c|c|c|c|c|c|c|c|c|c|c|c|}
\hline & $c_{2}$ & $V_{G}^{*}$ & $K_{B}^{+}$ & $V_{B}^{+}$ & $K_{B}^{*}$ & $V_{B}^{*}$ & $K_{B_{t}}$ & $V_{B_{t}}$ & $c_{2} / r$ & $s V_{B}^{*}$ & $F_{B_{t}}\left(V_{B_{t}}, K_{B_{t}}\right)$ \\
\hline$\gamma=0.1$ & 1.9222 & 247 & 180 & 370 & 180 & 288 & 220 & 180 & 38 & 5.76 & 45.30 \\
\hline$\gamma=0.2$ & 1.9222 & 247 & 160 & 329 & 160 & 247 & 220 & 180 & 38 & 4.94 & 44.72 \\
\hline
\end{tabular}

We have concluded that the government should have defined a greater value for the contractual penalty than the one actually enforced in the contract. The optimal contractual penalty is $c_{2}^{*}=2.9087$ : this is the value for the legal penalty that moves the selected bidder cash-flows trigger, $V_{B}^{+}=370$ downwards to perfectly meet the government cashflows trigger, $V_{G}^{*}=247$. Thus, the optimal contractual penalty, $c^{*}=2.9087$ assumes a greater value than the one included in the contract, i.e., $c_{2}=1.9222$. Hence, overestimating the comparative efficiency factor results in the definition of a below-optimal level for the contractual penalty, leading the selected bidder cash-flows trigger to be placed

is determined using a system of simultaneous equations similar to the one composed by equations (20), (21) and (22), i.e., the ones we used to derive the government expectation about the private firm investment opportunity. Please refer to the Appendix for further details. 
above the government cash-flows trigger. In fact, by setting the government construction costs, $K_{G}^{*}=200$, the selected bidder construction costs trigger is $K_{B}^{*}=180$ for $\gamma=0.1$ and its cash-flows trigger, $V_{B}^{*}=288$, considering the value of the penalty included in the contract form, $c_{2}=1.9222$. Since the selected bidder will have a higher cash-flows trigger than the government predicted, the value of social costs will be beyond the level the government considers to be acceptable. The government was prepared to accept social costs of $s=4.94$ in our example but, because the cash-flows trigger value is higher than the government expected, the selected bidder is causing the social costs to be $s=5.76$, which means that the population will have to bear an additional value of social costs of $s=0.82$. Yet, the fact that the contractual penalty is below its optimal level results in a more valuable option to invest for the selected bidder "vis-a-vis" with the scenario where the contractual penalty written down in the contract is optimal. The information included in Table 8 confirms such. Assuming that the pair of observed values, at time $t,\left\{K_{B_{t}} ; V_{B_{t}}\right\}=\{220 ; 180\}$, the value of the selected bidder investment opportunity, $F_{B}\left(K_{B}, V_{B}\right)$, at time $t$ equals 45.30 , whereas $F_{B}\left(K_{B}, V_{B}\right)$, at time $t$, in the scenario where the legal penalty written down in the contract is optimal, equals 44.72. This numerically demonstrates that the value of the option to invest is more valuable in the presence of a below-optimal contractual penalty. Since we believe that rational bidders will offer higher prices as a direct consequence of holding a more valuable option to invest, the government would, therefore, receive a higher price. However, the additional revenue the government would receive would also entail a cost: the higher value of social costs the population would have to bear. We argue that the government would prefer to receive a lower price and ensure that the value of social costs, previously defined as being tolerable, would not be exceeded. Hence, the scenario where a below-optimal contractual penalty value is considered will produce effects, to the government, which we believe the government would prefer to avoid.

\subsection{The Effects of Including an Above-Optimal Penalty Value in the Contract}

Figure 4 illustrates the impact of underestimating the selected bidder comparative efficiency on the optimal contractual penalty. We assume, in this scenario, that the selected bidder efficiency factor is, in fact, $\gamma=0.3$. Like in the previous scenario, we consider that the project dimension is given by $K_{G}^{*}=200$. 
Figure 4: the impact of underestimating the comparative efficiency on the optimal contractual penalty

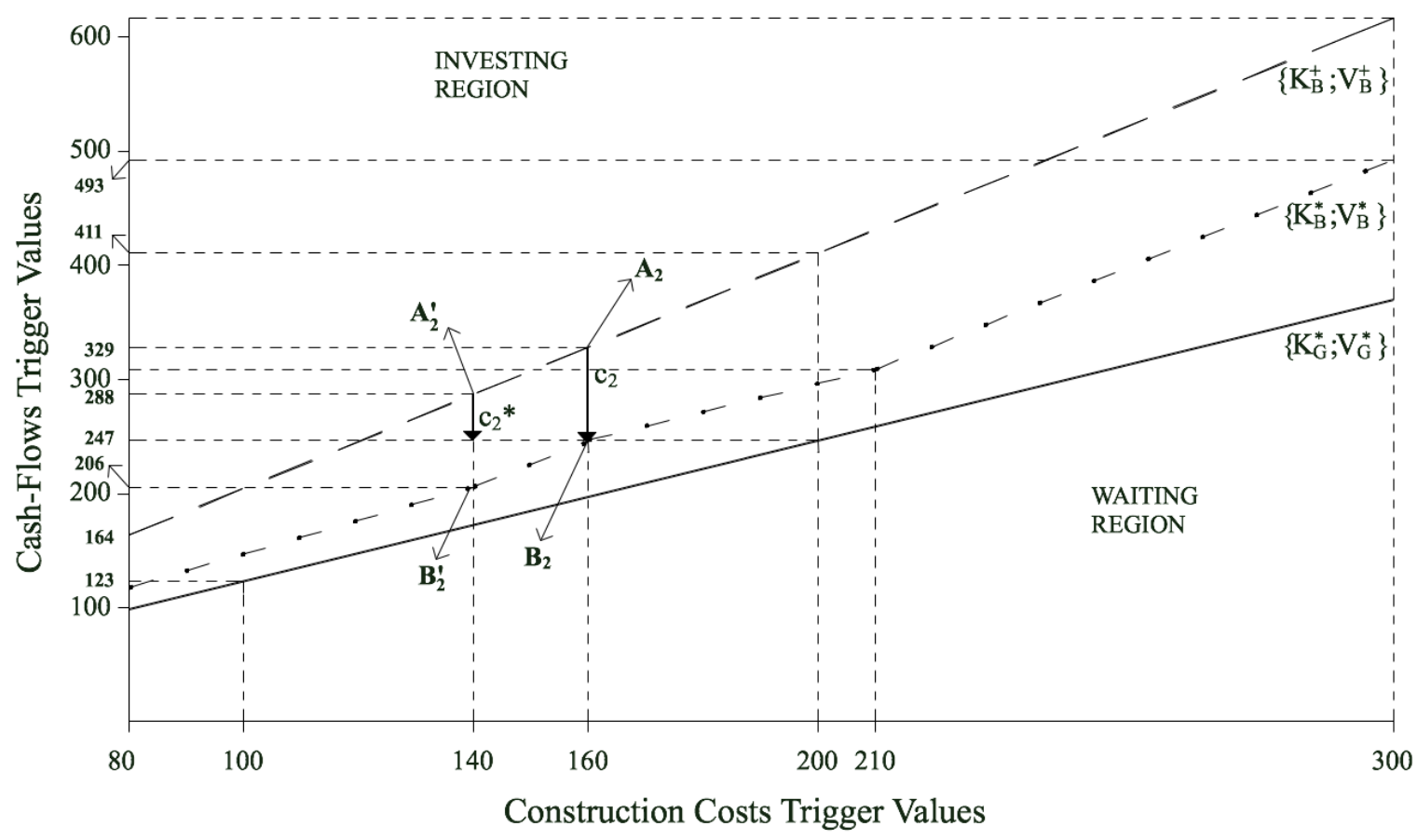

In Figure 4 above, the point $A_{2}$, with coordinates $\left\{K_{B}^{+} ; V_{B}^{+}\right\}=\{160 ; 329\}$, represents the selected bidder pair of triggers before considering the effect of the contractual penalty and assuming the efficiency factor estimated by the government $(\gamma=0.2)$. The coordinates of point $B_{2}$ represent the selected bidder pair of triggers, $\left\{K_{B}^{*} ; V_{B}^{*}\right\}=\{160 ; 247\}$, after considering the impact of the value of the legal penalty included in the contract, $c_{2}=$ 1.9222. By including this penalty value in the contract, the government expected the contractual penalty $c_{2}=1.9222$ to be perfectly capable of moving the selected bidder cash-flows trigger downwards, from $V_{B}^{+}=329$ to $V_{B}^{*}=247$ and, thus, to perfectly meet the government cash-flows trigger, $V_{G}^{*}=247$. Hence, the government expected the selected bidder to invest in point $B_{2}$, with coordinates $\left\{K_{B}^{*} ; V_{B}^{*}\right\}=\{160 ; 247\}$. However, since we are considering that the government has underestimated the selected bidder efficiency factor - which is $\gamma=0.3$ and not $\gamma=0.2$ - then the selected bidder construction costs trigger is $K_{B}^{*}=140$ and his or her corresponding cash-flows trigger, $V_{B}^{*}=206$. This pair of triggers is represented in Figure 4 by point $B_{2}^{\prime}$, with coordinates $\left\{K_{B}^{*} ; V_{B}^{*}\right\}=\{140 ; 206\}$. In Figure 4, is visible that the value of the legal penalty enforced in the contract, $c_{2}$ is too high: the impact in moving the selected bidder cash-flows trigger from $V_{B}^{+}=329$ to $V_{G}^{*}=247$ was too strong and moved the trigger to $V_{B}^{*}=206$. We thus conclude that the optimal value for the contractual penalty needs to be smaller, in order to perfectly align the two cash-flows triggers. For such purpose to be accomplished, the optimal value 
for the contractual penalty needs to be $c_{2}^{*}=0.9523$, a lower value than the one actually included in the contract, $c_{2}=1.9222$.

Table 9 includes a set of representative values aiming to demonstrate the effects, to government, of including an above-optimal contractual penalty in the contract form. As in the previous scenario, we consider that the project dimension is given by $K_{G}^{*}=200$ and, also, that the pair of observed values in the market, at time $t$ for the selected bidder construction costs trigger and cash-flows trigger, is $\left\{K_{B_{t}} ; V_{B_{t}}\right\}=\{220 ; 180\}$, which means that the selected bidder decision to invest, at time $t$, is situated in the waiting region.

Table 9: the effects, to the government, of underestimating the comparative efficiency

\begin{tabular}{|c|c|c|c|c|c|c|c|c|c|c|c|}
\hline & $c_{2}$ & $V_{G}^{*}$ & $K_{B}^{+}$ & $V_{B}^{+}$ & $K_{B}^{*}$ & $V_{B}^{*}$ & $K_{B_{t}}$ & $V_{B_{t}}$ & $c_{2} / r$ & $s V_{B}^{*}$ & $F_{B_{t}}\left(V_{B_{t}}, K_{B_{t}}\right)$ \\
\hline$\gamma=0.2$ & 1.9222 & 247 & 160 & 329 & 160 & 247 & 220 & 180 & 38 & 4.94 & 44.72 \\
\hline$\gamma=0.3$ & 1.9222 & 247 & 140 & 288 & 140 & 206 & 220 & 180 & 38 & 4.12 & 43.42 \\
\hline
\end{tabular}

Since the selected bidder is more efficient than the government predicted (in our example, the selected bidder's real comparative efficiency is $\gamma=0.3$ ), we concluded that the government should have defined a contractual penalty, $c_{2}^{*}=0.9523$, thus smaller than the one actually enforced in the contract, $c_{2}=1.9222$. Consequently, the selected bidder cashflows trigger assumes a lower value, $V_{B}^{*}=206$, leading to a reduction in the level of social costs. In fact, the government predicted as acceptable a value for social costs, $s=4.94$ and, according to this scenario, the value of social costs is $s=4.12$. We recognize that a reduction in the value of social costs results in a benefit for the population and we argue that the government will welcome any benefit for the population that may rise, provided that such benefit does not entail a cost. ${ }^{18}$ However, this benefit for the population involves a cost to the government. Since the penalty value included in the contract form is lower than the optimal value, we expect bidders to act rationally and offer a lower bid price to the government as a consequence of holding a less valuable investment opportunity, when compared with the case where the value of the legal penalty included in the contract form is optimal. In fact, the selected bidder option to invest, at time $t, F_{B_{t}}\left(V_{B_{t}}, K_{B_{t}}\right)$ equals 43.42, whereas the value of the same option in the case the government has estimated correctly the comparative efficiency is, at time $t$, equal to 44.72. Therefore, in this scenario, the government will most likely receive a lower price. We recognize that one might

\footnotetext{
${ }^{18}$ This is exactly the case where the comparative efficiency factor is strong enough to naturally place the selected bidder cash-flows trigger below the government cash-flows trigger, without the need of imposing a contractual penalty.
} 
consider that the decrease in the bid price the selected bidder will probably offer actually compensates the benefit that derives from the reduction in the value of social costs (this reduction is equal to 0.82 ). However, we argue that the government will prefer to accept a higher level of social costs until the level determined has being tolerable in the first place, and not expose itself to the possibility of incurring in the loss that results from receiving a lower bid price than the one the government would receive, if the value of the legal penalty included in the contract was, in fact, optimal.

\section{Part III}

\section{Conclusions}

The suggested model is based on a contractual framework, in the context of a BOT project, where the government grants leeway to the selected bidder regarding the timing of the project implementation. However, this flexibility may entail a cost, since a legal penalty is contractual enforced if the selected bidder does not implement the project immediately. Aiming to determine the optimal value for this contractual penalty, we applied a twofactor uncertainty approach, where both the facility construction costs and the present value of cash-flows to be generated by subsequent operations follow Geometric Brownian Motions that are possibly correlated.

We have assumed that the government is less efficient than the private firm in constructing the project facility and we have also considered the existence of social costs, i.e., the costs that correspond to the loss of social welfare occurred from the moment the project should have been implemented and services being provided to its users and the moment the project is actually completed. The government's purpose is to ensure that the selected bidder will invest when his or her cash-flows trigger has the same value of the government cash-flows trigger, if the government decided to conduct the project.

To determine the optimal level for the contractual penalty, we derived the government decision to invest and the government expectation about the private firm decision to invest. As the later does not support homogeneity of degree one in the corresponding boundary conditions, due to the consideration of the legal penalty in the value of the investment opportunity, we followed Adkins and Paxson (2011) solution and constructed a set of three simultaneous equations, which enabled us to define the private firm discriminatory boundary, i.e., the boundary that separates the private firm's waiting region from the private firm's investing region. We then reached an optimal level for the contractual penalty 
"per unit" of cost, since there is proportionality between the optimal value for the contractual penalty and the value assumed by the facility construction costs.

Sensitivity analysis performed demonstrated that the greater the level of social costs the sooner one expects the government would invest, since the consideration of higher levels of social costs result in lower values for the government cash-flows trigger. The analysis also revealed that there is a level for the comparative efficiency above which there is no need to include a penalty in the contract, since such level of efficiency factor, for the level of social costs considered, naturally moves the private firm cash-flows trigger downwards to perfectly meet the government cash-flows trigger. Sensitivity analysis also led us to conclude that changes in the correlation coefficients have a strong expected impact on the optimal contractual penalty. As both coefficients assume greater values, the value of the optimal penalty decreases since one expects that stronger correlations will lead to lower cash-flows triggers, both for the government and the private entity.

Finally, we examined the effects that overestimating or underestimating the comparative efficiency factor produces in the value of the optimal contractual penalty. We concluded that overestimating the efficiency factor results in the determination of a below-optimal value for the contractual penalty, and that underestimating this same factor will lead to the inclusion of an-above optimal value for the legal penalty in the contract form. Being so, since overestimating (underestimating) the value for the comparative efficiency factor will result in the inclusion of a below-optimal (above-optimal) value for the legal penalty in the contract, then the selected bidder cash-flows trigger will be greater (smaller) than the government cash-flows trigger. Since the optimal penalty is defined as being the one that ensures the selected firm has the same cash-flows trigger the government would have, if the government decided to undertake the project, we then concluded that the government's purpose will never be accomplished if the comparative efficiency factor is not estimated with full accuracy. 


\section{Appendix. The Selected Bidder Decision to Invest}

Let $F_{B}\left(K_{B}, V_{B}\right)$ denote the value of the selected bidder investment opportunity, where $K_{B}$ designates the facility construction costs and $V_{B}$ the value of the cash-flows to be generated by operating the subsequent activities. Both stochastic variables follow geometric Brownian motions that are possibly correlated:

$$
\begin{gathered}
d V_{B}=\alpha_{V_{B}} V_{B} d t+\sigma_{V_{B}} V_{B} d z_{V_{B}} \\
d K_{B}=\alpha_{K_{B}} K_{B} d t+\sigma_{K_{B}} K_{B} d z_{K_{B}} \\
E\left(d z_{V_{B}} d z_{K_{B}}\right)=\rho_{B} d t
\end{gathered}
$$

where $\alpha_{V_{B}}$ and $\alpha_{K_{B}}$ are the drift parameters, $d t$ is the time interval, $\sigma_{V_{B}}$ and $\sigma_{K_{B}}$ the standard deviations for each of the variables, $d z_{V_{B}}$ and $d z_{K_{B}}$ the increments of standard Wiener processes for $V_{B}$ and $K_{B}$ and $\rho_{B}$ is the correlation coefficient between $V_{B}$ and $K_{B}$. Under risk-neutrality, $F_{B}\left(V_{B}, K_{B}\right)$ must satisfy the following partial differential equation:

$$
\begin{aligned}
& \frac{1}{2} \sigma_{V_{B}}^{2} V_{B}^{2} \frac{\partial^{2} F_{B}}{\partial V_{B}^{2}}+ \frac{1}{2} \sigma_{K_{B}}^{2} K_{B}^{2} \frac{\partial^{2} F_{B}}{\partial K_{B}^{2}}+\rho_{B} \sigma_{V_{B}} \sigma_{K_{B}} V_{B} K_{B} \frac{\partial^{2} F_{B}}{\partial V_{B} \partial K_{B}}+ \\
&\left(r-\delta_{V_{B}}\right) V_{B} \frac{\partial F_{B}}{\partial V_{B}}+\left(r-\delta_{K_{B}}\right) \frac{\partial F_{B}}{\partial K_{B}}-r F_{B}-c=0
\end{aligned}
$$

where $r$ is the risk-free interest rate, $c$ is the value of the legal penalty enforced in the contract, $\delta_{V_{B}}$ and $\delta_{K_{B}}$ are the rates of return-shortfall for $V_{B}$ and $K_{B}$, respectively. $\delta_{V_{B}}$ and $\delta_{K_{B}}$ are given by the following equations:

$$
\delta_{V_{B}}=r-\alpha_{V_{B}}
$$




$$
\delta_{K_{B}}=r-\alpha_{K_{B}}
$$

The partial differential equation above has a non-homogeneous part, $c$, being the rest of the equation homogeneous. The general solution for the homogeneous part of the partial equation, $F_{B}^{H}\left(V_{B}, K_{B}\right)$ is given by:

$$
F_{B}^{H}\left(V_{B}, K_{B}\right)=A_{9} V_{B}^{\beta^{+}} K_{B}^{\eta^{+}}+A_{10} V_{B}^{\beta^{+}} K_{B}^{\eta^{-}}+A_{11} V_{B}^{\beta^{-}} K_{B}^{\eta^{+}}+A_{12} V_{B}^{\beta^{-}} K_{B}^{\eta^{-}}
$$

where $A_{9}, A_{10}, A_{11}$ and $A_{12}$ are constants that need to be determined. $\beta^{+}, \beta^{-}, \eta^{+}$and $\eta^{-}$are the four roots of an elliptical equation, which is the two-factor equivalent of the one-factor stochastic model quadratic equation presented in Dixit and Pindyck (1994). The elliptical equation is:

$$
\begin{aligned}
Q(\beta, \eta)= & \frac{1}{2} \sigma_{V_{B}} \beta(\beta-1)+\frac{1}{2} \sigma_{K_{B}}^{2} \eta(\eta-1)+ \\
& \rho_{B} \sigma_{V_{B}} \sigma_{K_{B}} \beta \eta+\left(r-\delta_{V_{B}}\right) \beta+\left(r-\delta_{K_{B}}\right) \eta-r=0
\end{aligned}
$$

The function $Q(\beta, \eta)=0$ defines an ellipse. ${ }^{19}$ The equation above has four quadrants, to which of them corresponds a pair of the four roots we mentioned, i.e., the four points where the elliptic function meets the axes. If we consider the absorbing barriers $F_{B}(0,0)$, $F_{B}\left(0, K_{B}\right)$, then $A_{3}=A_{4}=0$. This condition holds because the option to invest is worthless if the present value of the future cash-flows to be generated is zero. Likewise, for $F_{B}\left(V_{B}, K_{B}\right)$, and as $K_{B}$ becomes infinitely large for any value of $V_{B}$, the option value is also zero. To respect this condition, we need to set constant $A_{1}=0$, leaving only constant $A_{2} \neq 0$. Consequently, in our case the quadrant of interest is the second one, i.e., the one that corresponds to the pair of roots $\left\{\beta^{+}, \eta^{-}\right\}$. The general solution for the homogeneous part of the partial differential equation above, $F_{B}^{H}\left(V_{B}, K_{B}\right)$ is then reduced and takes the following form:

$$
F_{B}^{H}\left(V_{B}, K_{B}\right)=A_{10} V_{B}^{\beta^{+}} K_{B}^{\eta^{-}}
$$

The particular solution we propose for the non-homogeneous part of the partial differential equation, $F_{B}^{N H}$ is given by the following equation:

\footnotetext{
${ }^{19}$ Please refer to Adkins and Paxson (2011) for further details.
} 


$$
F_{B}^{N H}=-\frac{c}{r}
$$

Joining the homogeneous and non-homogeneous solutions, we obtain the following expression which satisfies the whole partial differential equation:

$$
F_{B}^{H}\left(V_{B}, K_{B}\right)+F_{B}^{N H}=F_{B}\left(V_{B}, K_{B}\right)=A_{10} V_{B}^{\beta^{+}} K_{B}^{\eta^{-}}-\frac{c}{r}
$$

Hence, the value-matching condition will be given by:

$$
F_{B}\left(V_{B}^{*}, K_{B}^{*}\right)=A_{10} V_{B}^{*^{\beta^{+}}} K_{B}^{*^{\eta^{-}}}-\frac{c}{r}=V_{B}^{*}-K_{B}^{*}
$$

Since the value-matching condition above does not support homogeneity of degree one on both sides (which means that $\beta^{+}+\eta^{-} \neq 1$ ), we follow Adkins and Paxson (2011) solution and construct a set of three simultaneous equations. The first equation is the elliptical equation, presented above and reproduced below:

$$
\begin{aligned}
Q(\beta, \eta)= & \frac{1}{2} \sigma_{V_{B}}^{2} \beta(\beta-1)+\frac{1}{2} \sigma_{K_{B}}^{2} \eta(\eta-1)+ \\
& \rho \sigma_{V_{B}} \sigma_{K_{B}} \beta \eta+\left(r-\delta_{V_{B}}\right) \beta+\left(r-\delta_{K_{B}}\right) \eta-r=0
\end{aligned}
$$

The other two equations are the two smooth-pasting conditions derived from the valuematching condition above. The first smooth-pasting condition is the first-order derivative of the value-matching condition, in respect to $V_{B}^{*}$. After applying some rules of calculus, we reach the expression for the first smooth-pasting condition, which is given by the following equation:

$$
\beta^{+}\left(V_{B}^{*}-K_{B}^{*}+\frac{c}{r}\right)=V_{B}^{*}
$$

The second smooth-pasting condition is the first-order derivative of the value matching condition, in respect to $K_{B}^{*}$. Likewise, after applying some rules of calculus, we reach the expression for the second smooth-pasting condition, given by the following equation: 


$$
\eta^{-}\left(V_{B}^{*}-K_{B}^{*}+\frac{c}{r}\right)=-K_{B}^{*}
$$

The set of simultaneous equations is thus formed by the elliptical equation and the two smooth-pasting conditions. We need to set $K_{B}^{*}$ since we are in the presence of four uncertains $\left(K_{B}^{*}, V_{B}^{*}, \beta^{+}, \eta^{-}\right)$and only have three equations available. Firstly, we solve the set of simultaneous equations considering that $c=0$. This procedure enables us to obtain the selected bidder cash-flows trigger in the absence of a contractual penalty, which we denote by $V_{B}^{+}$. Secondly, we solve the same set of simultaneous equations to determine the exact value for $c$ that moves $V_{B}^{+}$downwards to perfectly meet the government cash-flows trigger, $V_{G}^{*}$. By repeating this process many times attributing different values for $K_{B}^{*}$, we are able to define a discriminatory boundary separating the selected bidder investing region from the selected bidder waiting region, formed by a set of countless pairs, $\left\{K_{B}^{*} ; V_{B}^{*}\right\}$.

The selected bidder should invest when both triggers, $K_{B}^{*}$ and $V_{B}^{*}$ are simultaneously attained, i.e., $\left\{K_{B}, V_{B}\right\} \geq\left\{K_{B}^{*}, V_{B}^{*}\right\}$. When both triggers are simultaneously attained, the value of the option to invest equals the project's expected net present value. Otherwise, the selected bidder should wait and defer the investment. Hence, the value of the selected bidder investment opportunity is given by:

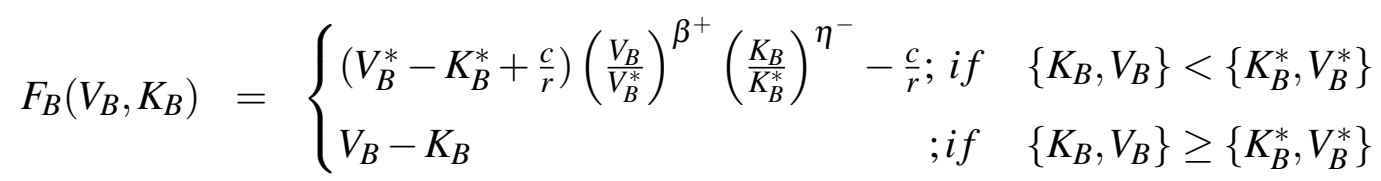

Therefore, the value of the selected bidder option to invest in a project where a legal penalty, $c$ is enforced is given by the same function we presented when we derived the government expectation about the private firm decision to invest, $F_{P}\left(V_{P}, K_{P}\right)$.

Figure 1 shows the selected bidder discriminatory boundary, assuming that the value of the legal penalty included in the contract is $c_{2}=1.9222$. We consider values for $K_{B}^{*}$ ranging from 80 to 480 and also consider that: $\sigma_{V_{B}}=0.15 ; \sigma_{K_{B}}=0.10 ; \rho_{B}=0 ; r=0.05$; $\delta_{B_{V}}=\delta_{B_{K}}=0.03 ; \gamma=0.2$. 
Figure 1: Appendix: the selected bidder discriminatory boundary

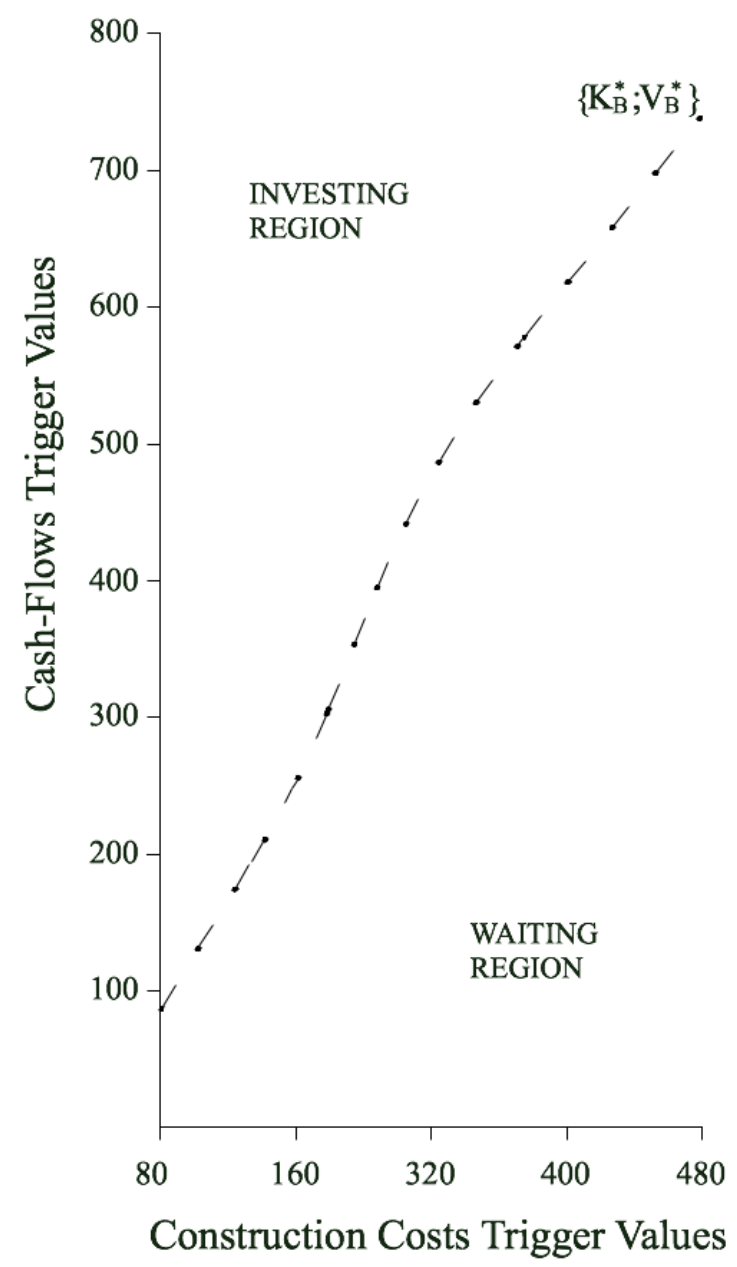

The discriminatory boundary included in Figure 1 was determined assuming that the value of the contractual penalty is the same, regardless of the amount considered for selected bidder construction costs. If the selected bidder had information about the value of the contractual penalty "per unit" of cost, then his or her discriminatory boundary will be a straight line with a positive slope. However, since the selected bidder only has information about the value, in absolute terms, of the contractual penalty included in the contract form, then the impact of a non-optimal value for the legal penalty in the system of simultaneous equations similar to the one composed by equations (20),(21) and (22) (the ones used to determine the government expectation about the private firm decision to invest and the corresponding discriminatory boundary), results in a non-linear relationship between the selected pairs of triggers, for any project dimension we may consider. Hence, the configuration of the selected bidder discriminatory boundary in Figure 1 reflects the impact of the non-homogeneous term, $c$, included in the partial differential equation above and, therefore, in the system of simultaneous equations used to determine the selected bidder 
discriminatory boundary. 


\section{References}

Adkins, R. and D. Paxson: (2011), 'Renewing Assets with Uncertain Revenues and Operating Costs'. Journal of Financial and Quantitative Analysis Vol. 46, No 3, 785-813.

Algarni, A. M., D. Arditi, and G. Polat: (2007), 'Build-Operate-Transfer in Infrastructure Projects in the United States'. Journal of Construction Engineering and Management Vol. 133, $\mathbf{N}^{0} 10$, 728-735.

Alonso-Conde, A., C. Brown, and J. Rojo-Suarez: (2007), 'Public-Private Partnerships: Incentives, Risk Transfer and Real Options'. Review of Financial Economics Vol. 16, No 4, 335-349.

Armada, M. J. R., P. Pereira, and A. Rodrigues: (2013), 'Optimal Investment with Two-Factor Uncertainty'. Mathematics and Financial Economics Forthcoming.

Armada, M. J. R., P. J. Pereira, and A. Rodrigues: (2012), 'Optimal Subsidies and Guarantees in Public-Private Partnerships'. The European Journal of Finance Vol. 18, No 5, 469-495.

Brandao, L. E. and E. Saraiva: (2008), 'The Option Value of Government Guarantees in Infrastructure Projects'. Construction Management and Economics Vol. 26, № 11, 1171-1180.

Caselli, S., S. Gatii, and A. Marciante: (2009), 'Pricing Final Indemnification Payments to Private Sponsors in Project-Financed Public-Private Partnerships: An Application of Real Options Valuation'. Journal of Applied Corporate Finance Vol. 21, No 3, 95-106.

Cheah, C. and J. Liu: (2006), 'Valuing Governmental Support in Infrastructure Projects as Real Options Using Monte Carlo Simulation'. Construction Management and Economics Vol. 24, $\mathbf{N}^{0}$ 5, 515-54.

Chiara, N., M. J. Garvin, and J. Vecer: (2007), 'Valuing Simple Multiple-Exercise Real Options in Infrastructure Projects'. Journal of Infrastructure Systems Vol. 13, No 2, 97-104.

Coase, R. H.: (1960), 'The Problem of Social Cost'. Journal of Law and Economics Vol. 3, No 1, $1-44$.

Constantinides, G.: (1978), 'Market Risk Adjustment in Project Valuation'. Journal of Finance Vol. 33, No 2, 603-616.

Dixit, A. and R. Pindyck: (1994), Investment Under Uncertainty. New Jersey: Princeton University Press.

Ferreira, D. and K. Khatami: (1996), 'Financing Private Infrastructure in Developing Countries'. World Bank - Discussion Papers 343, 1-32. 
Ho, S. P. and L. Y. Liu: (2002), 'An Option Pricing-Based Model for Evaluating the Financial Viability of Privatized Infrastructure Projects'. Construction Management and Economics Vol. 20, $\mathbf{N}^{0} 2,143-156$.

Huang, Y. and S. Chou: (2006), 'Valuation of the Minimum Revenue Guarantee and the Option to Abandon in BOT Infrastructure Projects'. Construction Management and Economics Vol. 24, $\mathbf{N}^{\circ} 4,379-389$.

Huang, Y.-L. and C.-C. Pi: (2009), 'Valuation of Multi-Stage BOT Projects Involving Dedicated Asset Investments: A Sequential Compound Option Approach'. Construction Management and Economics Vol. 27, N 7, 653-666.

Kwak, Y. H., Y. Y. Chih, and C. W. Ibbs: (2009), 'Towards a Comprehensive Understanding of Public Private Partnerships for Infrastructure Development'. California Management Review Vol. 51, No 2, 51-78.

Liu, J. and C. Y. J. Cheah: (2009), 'Real Option Application in PPP/PFI Project Negotiation'. Construction Management and Economics Vol. 27, No 4, 331-342.

Maskin, E. and J. Tirole: (2008), 'Public-Private Partnerships and Government Spending Limits'. International Journal of Industrial Organization Vol. 26, No 2, 412-420.

McDonald, R. and D. Siegel: (1986), 'The Value of Waiting to Invest'. The Quarterly Journal of Economics Vol. 101, No 4, 707-728.

Paxson, D. and H. Pinto: (2005), 'Rivalry under Price and Quantity Uncertainty'. Review of Financial Economics Vol. 14, No 3-4, 209-224.

Pereira, P., A. Rodrigues, and M. R. Armada: (2006), 'The Optimal Timing for the Construction of an International Airport: a Real Options Approach with Multiple Stochastic Factors and Shocks'. 10th Real Options Conference, NewYork. pp. 1-20.

Rus, G. and G. Nombela: (2007), 'Is Investment in High Speed Rail Socially Profitable?'. Journal of Transport Economics and Policy Vol. 41, N 1, 3-23.

Shan, L., M. Garvin, and R. Kumar: (2010), 'Collar Options to Manage Revenue Risks in Real Toll Public-Private Partnership Transport Projects'. Construction Management and Economics Vol. 28, N 10, 1057-1059.

Shen, L. and Y. Z. Wu: (2005), 'Risk Concession Model for Build-Operate-Transfer Contract Projects'. Journal of Construction Engineering and Management Vol. 131, No 2, 211-220.

Shen, L. Y., H. LI, and Q. M. Li: (2002), 'Alternative Concession Model for Build Operate Transfer Contract Projects'. Journal of Construction Engineering and Management Vol.128, $\mathbf{N}^{\circ} 4$, 326-330. 
Trigeorgis, L.: (1996), Real Options: Managerial Flexibility and Strategy in Resource Allocation. Boston: MIT Press.

Zhang, X. Q. and M. M. Kumaraswamy: (2001), 'Procurement Protocols for Public-Private Partnered Projects'. Journal of Construction Engineering and Management Vol. 127, No 5, 351358. 